\title{
Artificial Neural Network Controlled GMAW System: Penetration and Quality Assurance in a Multi-Pass Butt Weld Application
}

\author{
Sakari Penttilä ${ }^{1} \cdot$ Paul Kah $^{1} \cdot$ Juho Ratava $^{1} \cdot$ Harri Eskelinen $^{1}$ \\ Received: 28 March 2019 / Accepted: 16 September 2019/Published online: 12 November 2019 \\ (C) The Author(s) 2019
}

\begin{abstract}
Intelligent welding parameter control is fast becoming a key instrument for attaining quality consistency in automated welding. Recent scientific breakthroughs in intelligent systems have turned the focus of adaptive welding control to artificial intelligencebased welding parameter control. The aim of this study is to combine artificial neural network (ANN) decision-making software and a machine vision system to develop an adaptive artificial intelligence (AI)-based gas metal arc welding (GMAW) parameter control system. The machine vision system uses a laser sensor to scan the upcoming seam and gather seam profile data. Based on further processing of the seam profile data, welding parameters are optimized by the decision-making system. In this work, the developed system is tested in a multivariable welding condition environment and its performance is evaluated. The quality of the welds was consistent and surpassed the required quality level. Additionally, the heat-affected zone (HAZ) was evaluated by microscopy, X-ray, and scanning electron microscope (SEM) imaging. It is concluded that the developed ANN system is suitable for implementation in automated applications, can improve quality consistency and cost efficiency, and reduce required workpiece preparation and handling.
\end{abstract}

Keywords Intelligent welding · Adaptive welding · Artificial neural network · Machine vision · GMAW · Laser sensor

\section{Introduction}

In the globalized economy, productivity and cost-efficiency have become central aspects of production, and increasingly fierce competition in manufacturing is motivating the welding industry to use lighter, more optimized structures and increase the level of automation. Although welding automation increases productivity, current welding automation systems suffer from several major drawbacks. A primary concern in automated welding is the inability to adapt effectively to varying welding conditions, leading to inconsistent welding quality. Hence, the more stringent weld quality requirements of optimized structures, resulting from the use of thinner materials, high-strength steels and reduction of weld material, are difficult to achieve [1-3]. Additionally, the quality and penetration

Sakari Penttilä

sakari.penttila@lut.fi; http://www.lut.fi

1 Laboratory of Welding Technology, LUT University, P.O. Box 20, FI-53851 Lappeenranta, Finland inconsistency, caused by the inability to adapt, affects drastically to fatigue life and strength properties of the weld joint [4-7]. Traditionally, meeting such quality requirements have been approached by precise machining and fitting of the workpieces. However, precise manufacturing tolerances are often difficult to achieve, and the extra work required can increase production costs significantly. Additionally, heat distortions may reduce or increase the root gap of the seam during welding, creating constantly changing welding conditions $[8,9]$. A more effective and cost-efficient way to reach the demanded quality requirements is to mimic manual welding behavior, i.e., sense the upcoming seam and optimize the welding parameters according to the welding conditions [10-12]. It has been studied that welding of the root pass in butt weld is a challenging sequence. Even the slight changes in seam profile can lead to unacceptable weld quality and therefore adaptivity in welding control is required when using robotized or mechanized welding [13].

In the welding production point of view, the similar welds can be done with multiple processes and various different approaches, which increase the quality inconsistency. The inconsistency of the quality creates issues with life cycle 
analysis and other product properties [7, 14, 15]. .The welding industry is constantly trying to find solutions that enable automated systems to adapt to varying welding conditions and achieve consistent quality cost-efficiently. Adaptive welding systems have been developed that respond to varying welding conditions with single-parameter variation and linear fitting $[16,17]$. However, welding is a complicated multi-variable process where the ability to adapt to a single varying parameter is not sufficient to guarantee successful outcomes. Recent progress in multi-variable control systems has led research institutes and companies to make advances in the area of intelligent welding. Current advanced sensor technology provides accurate and comprehensive information about the welding process, and multi-variable parameter control has thus been approached with the use of AI decision-making systems. AI-based control systems have been integrated with various sensors such as laser sensors, thermal sensors, arc imaging, and acoustic sensors to address quality inconsistency in conventional automated welding [10,12, 13, 18-25].

Previous studies have reported the development of ANN systems capable of predicting the weld quality outcome [1, 10, 19, 26-33]. In these studies, ANNbased prediction has been studied considering bead width, bead height, and achieved depth of penetration of the weld. It has been found that ANN-based software can predict with precision the outcome of the weld in terms of penetration and bead shape. Collectively, these studies outline a critical role for intelligent decisionmaking in the welding manufacturing industry and highlight the potential of intelligent control of welding. However, although a remarkable amount of research has been carried out on AI welding systems, little work has been presented demonstrating the practical application of such systems. To begin to bridge this knowledge gap, practical examination and evaluation of an ANN system for welding are carried out in this study.

This study extends the previous study by Penttilä et al. [13], where an ANN welding parameter control system was developed and tested in practice. In this study, a machine vision system is combined with the ANN welding parameter control system to achieve a more consistent weld outcome and weld quality in varying welding conditions. The study seeks to develop an ANN-controlled robot welding system for multi-pass butt welding of $12 \mathrm{~mm} \mathrm{S420MC}$ plate without root support. The system is tested on varying root gap, root face, and shape and size of tack welds. Weld quality is tested with welding procedure tests, and the results are compared to previous studies.

A further aim of the study is to clarify how the developed ANN system adapts to varying welding conditions and tack welds in a robotized welding application. The following research issues are addressed:
1. Assessment of the capability of a laser sensor to sense the weld seam and identify welding conditions automatically using associated profile analysis software.

2. Determination of the performance and suitability of the ANN controlled welding system for a tack welded butt welds with varying welding conditions.

The ANN controlled intelligent welding process gathers information from sensors to get specific knowledge of welding conditions at specific points of the weld. To match the parameters for the welding conditions, decision-making software is used to evaluate the welding condition. The decision-making software correlates the sensed welding condition to a trained knowledge bank and determines the optimal welding parameters based on the training. The main feature of ANN control system is to combine the relation between the welding conditions and welding parameters and link them to produced welding quality.

The practical benefits of the developed system are that it extends the application field of mechanized and automated GMAW. The system can be used to ensure full penetration and consistent quality in butt weld applications, and it can decrease production time by reducing rework, scrap, and the need for root support. Furthermore, mechanized and automated GMAW can be extended to the welding of closed-shell structures, where the use of root support is restricted. Such structures are commonly found in naval beam production and the crane industry.

The article is divided into five sections: "Introduction," "Materials and methods," "Results and analysis," "Discussion," and last the "Conclusion." In the "Introduction" section background, the purpose of the study and research issues are addressed. Next, in "Materials and methods" section defines the used experimental setup and basis of the developed adaptive welding control system based on ANN. Added to that, the system layout is described in more detail followed by the welding experiment execution process description.

The results and analysis section consists of the results of ANN training process for the experiments. Next, the three verification experiments of ANN suitability are presented as a separate section. Each experiment represents a different type of root face and root gap conditions. After the separate experiments, the outcome of the combined experiments is presented and analyzed. Last, the quality verification of the experiments is presented.

The discussion section consists of the suitability of the study in a practical and in a theoretical point of view. Added to that, the findings related to research questions are introduced shortly. Last, the possible future studies are introduced. Finally, the conclusion of the study is presented where the main findings of the study are concluded and presented. 


\section{Materials and methods}

In this section, the materials and ANN controlled welding system layout are introduced. Furthermore, seam gathering, analysis, and the neural network training process are explained. Finally, the welding experiments are described.

\subsection{Materials and system layout}

The material chosen for the welding experiments was low alloy steel S420MC by SSAB. S420MC was chosen for the welding experiments because of its fine grain structure and good weld properties. A matched filler wire, Esab OK Autorod 12.50 with $1 \mathrm{~mm}$ diameter, was chosen, and hence, weld material tensile strength is equal to the base material. For good arc stability and low spatter, $8 \% \mathrm{CO}_{2}$ mixed argon gas was chosen as a shielding gas.

\subsection{Experimental setup}

Weld experiments were conducted using an $\mathrm{ABB}$ robot cell with Fronius welding equipment. A $12-\mathrm{mm}$ plate was welded with a $60^{\circ}$ single V-groove with root face butt weld in PA position. Torch distance of $18 \mathrm{~mm}$ was used with the welding speed varying from 4 to $7 \mathrm{~mm} / \mathrm{s}$. A laser sensor was integrated $93 \mathrm{~mm}$ in front of the welding torch with a scanning distance of $40 \mathrm{~mm}$ for seam scanning and tracking. Torch configuration and experimental setup can be seen in Fig. 1.

A commercially available seam tracking laser sensor (Meta SLS50-v1) was used to gather the image of the seam. The laser sensor uses a width of 1024 pixels as a line of sight with a refresh rate of $100 \mathrm{fps}$. To determine the values of the root gap and root face, the software was developed to analyze the raw data gathered from the laser sensor. To obtain seam information at specific coordinate points, the seam was scanned prior to welding and the data linked with the coordinate points gathered from the robot controller. By using a separate tool point for both laser sensor and welding torch, the data of scan and welding can be combined in a one-data file for each point

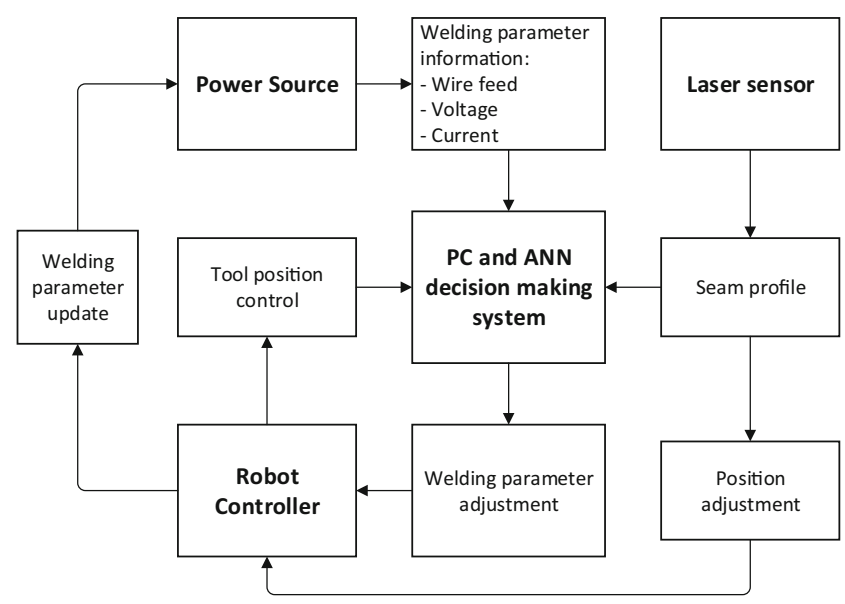

Fig. 2 Parameter control principle of the ANN decision-making system

of the weld. Based on the seam data, the developed ANN decision-making system was used to adapt the welding parameters in real time. The ANN decision-making software was developed using the Matlab neural network tool with a custom-made interface between the laser sensor, robot controller, and computer. The parameter control principle of the system is shown in Fig. 2.

\subsection{Seam profile gathering and analysis}

Seam profile data was gathered from the workpiece prior to welding with a scanning speed of $5 \mathrm{~mm} / \mathrm{s}$. To ensure constant scanning distance, the scanning sequence was carried out with a calibrated tool point. To increase the reliability of the measurements, single false readings of the profile measurements were filtered out by calculating the median of the collected data in a 0.5 $\mathrm{s}$ non-overlapping window. After each measurement cycle, the coordinate points were combined with the median of the seam profile data. The raw data of the seam was analyzed automatically after the scan using the developed analysis software. Root gap and root face values were defined at each point of the seam in
Fig. 1 Torch configuration and experimental setup of the case study. a Side view. b Front view

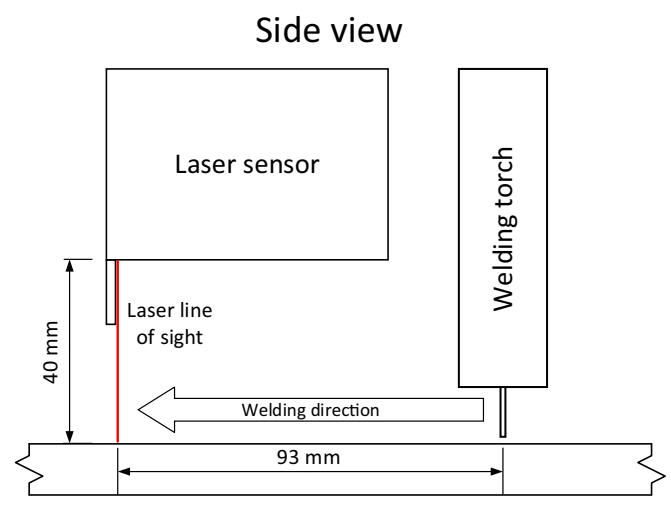

a

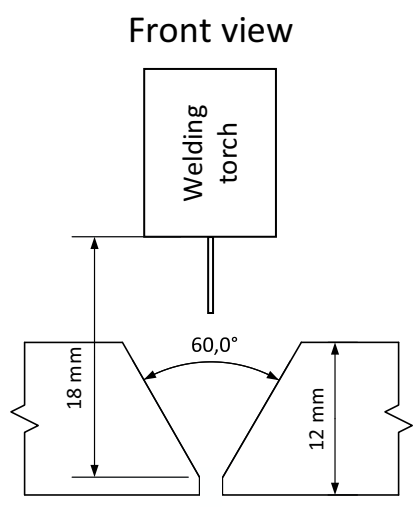

b 
Fig. 3 Machine vision image of the scanned seam with two tack welds

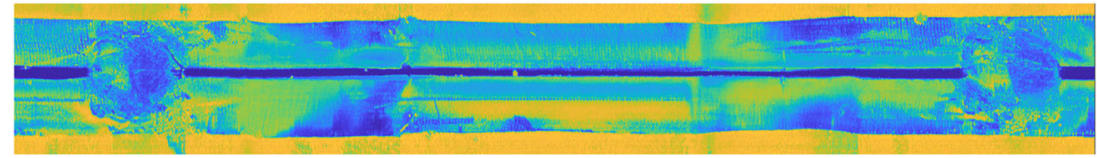

addition to the positions and shapes of the tack welds. After the analysis, the seam profile from the raw data was plotted for visual inspection to confirm the result of the automated evaluation (Fig. 3). The results of the scanning were validated by measuring gap manually with a feeler gauge. The laser measurement system described was developed in previous research [34].

The root gap of the seam was sensed as a nonreflected area in the middle of the image, which can be seen as a darker area in Fig. 3. The width of the root gap was calculated from the number of measurement points lacking the sensed reflection. From the gap edges, if the root gap is smaller than $0.6 \mathrm{~mm}$, the edges are located on adjacent pixels on image of the seam tracking sensor and it is not possible to see if the gap is closed or not. For the purpose of accurate analysis, the point of the seam was defined as a tack weld if the sensed root gap was smaller than $0.5 \mathrm{~mm}$. In order to identify the root face of the seam, the root face was calculated based on the already known plate thickness. The root face $(\mathrm{X})$ was measured by the height difference $\mathrm{Y}$ between the plate surface median and the lowest corner point of the detected seam (highest point of the root face) as illustrated in Fig. 4. The height difference sensed, $\mathrm{Y}$, is subtracted from the plate thickness (estimated to remain constant) to get the value $\mathrm{X}$ of the root face. A minor source of uncertainty in the calculation of the root face comes from varying plate thickness. The variation of the plate thickness cannot be measured in real time by the measurements conducted in the study.

\subsection{Neural Network configuration}

In the previous study by Penttilä et al. [13], thermal distribution data was used as an adjusting parameter for the neural network together with root gap measurement. A drawback of the temperature measurementbased approach is the delay in information generation because the sensor trails the torch. To rule out the
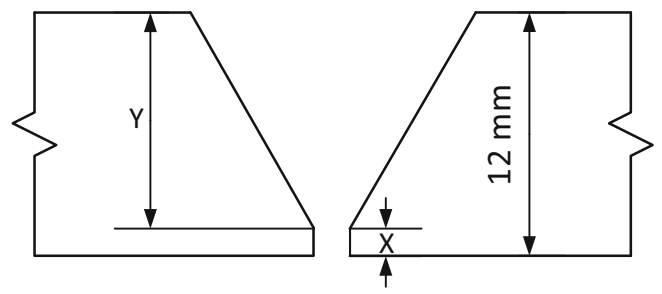

Fig. 4 Determination of the root face. $X=12 \mathrm{~mm}-\mathrm{Y}$ possibility of inconsistency in decision-making related to the delay, only laser sensor information was used in this study. The main variables in seam shape were considered to be the root gap and the root face as they play in a key role in controlling the depth of penetration.

It should be noted that a root gap, as well as a root face, is often a varying welding condition in butt weld applications, and they play a crucial role in terms of determining optimal parameters for the welding process. Narrow root gap and high root face require higher heat input to melt the root of the seam and get full penetration. Wider root gap and low root face often lead to excess penetration or even burn through if the heat input or arc pressure is too high. Consequently, the root face and root gap were chosen as input parameters for the ANN decision-making software. The learning technique of the neural network was offline supervised learning. To overcome possible overfitting of the ANN, network size and network layer configuration were optimized which is explained in more detail in "ANN training process." Information about the materials and system layout is given in Table 1.

Table 1 Materials and system layout

\begin{tabular}{ll}
\hline Material, plate thickness & S420 MC, 12 mm \\
\hline Filler material & Esab OK Autrod 12.50, Ø 1 mm \\
Welding process & GMAW (135) \\
Welding equipment & Fronius TPS 5000 \\
Joint type & Butt weld \\
Weld position & PA \\
Groove angle & $60^{\circ}$ \\
Root gap variation in experiments & $0.7-2.2 \mathrm{~mm}$ \\
$\quad$ (min - max) & \\
Root face variation in experiments & $0.9-2.6 \mathrm{~mm}$ \\
$\quad$ (min - max) & $4-7 \mathrm{~mm} / \mathrm{s}$ \\
Welding speed (min - max) & $92 \%$ Ar $+8 \% \mathrm{CO}_{2}$, AGA Mison \\
Welding gas and flow speed & $8,191 / \mathrm{min}$ \\
& $18 \mathrm{~mm}$ \\
Torch distance & Torch weaving with 3rd and 4th \\
Other remarks & pass \\
& Meta SLS50-v1 \\
Laser sensor & Backpropagation neural network \\
Neural network type & $2-20-20-2$ \\
Neural network configuration & Root gap, root face \\
Neural network input parameters & Wire feed, arc voltage \\
Neural network output parameters & \\
\hline
\end{tabular}


Fig. 5 Five-phase welding experiment process

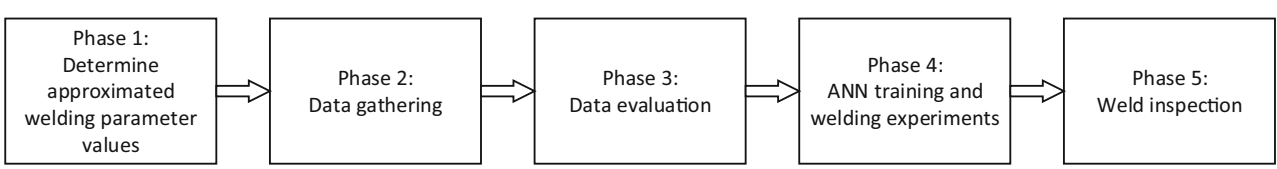

\subsection{Welding experiments execution process}

The welding experiments comprised five phases, shown in Fig. 5. The different phases of the process are explained in more detail in the following paragraphs.

The butt joint was welded with four passes in PA welding position. The root pass was controlled with the neural network decision-making system, and the other passes were welded with optimized consistent weld parameters. As the welding conditions do not vary significantly after the first pass, the welding was carried out with constant parameters for the buildup and final pass. Added to that, the reliability of the study was increased by not controlling the buildup and final pass. The third and the fourth pass were welded with torch weaving to achieve smoother bead shape. After each pass, no additional preparation or cleaning was done to simulate the fully automated welding sequence.

Phase 1:

The first step of the welding experiments is to determine approximate welding parameters that give adequate weld quality for different welding conditions (Fig. 6).

Phase 2:

The approximated parameters defined in phase 1 were used as the basis of the data gathering phase of the welding

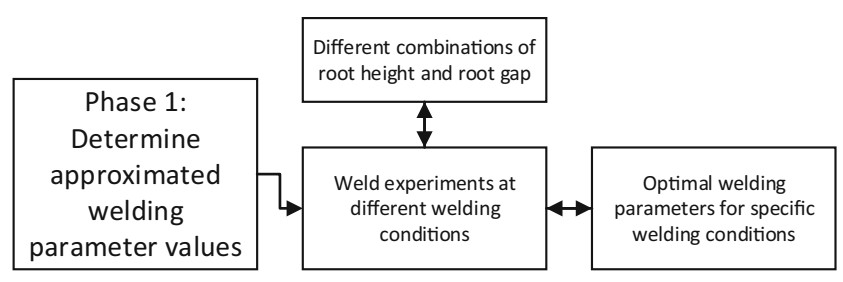

Fig. 6 Approximated welding values determination phase of the welding experiments

Fig. 7 Data gathering phase of the welding experiments experiments. First, the wire feed was varied while the arc voltage was kept constant. A suitable wire feed value was chosen by visual inspection. Next, the suitable wire feed (constant) was used while the voltage was varied for similar welding conditions. Similar experiments were conducted with various root gaps and root faces to accumulate more comprehensive data for the ANN training process. The data gathering process is illustrated in Fig. 7.

When generating the ANN training data, the workpieces were tack welded at both ends of the plate and in the middle of the seam to keep the heat distortions negligible. Before carrying out the welding experiments, the laser sensor was used to scan the seam to get profile information at specific coordinate points. In addition, different shapes of tack welds were used to define the optimal parameters to get consistent quality over the tack welds. The root gap and root face variation were minimal in the training sequence to avoid excess variation in the experiments. The training sequence was carried out with automated parameter variation at every $100 \mathrm{~mm}$, and total weld experiment length was $10 \mathrm{~m}$. The data from the welding process (wire feed, current, voltage, etc.) was gathered for the systems training process and combined with the seam data received from the laser sensor. The gathered data was linked with the coordinate position information from the robot controller every $0.5 \mathrm{~s}$. To create the knowledge bank for the ANN decision-making system, the welding data information coordinates were combined with the seam data information coordinates. The training and knowledge bank creation process is described in Fig. 8.

\section{Phase 3:}

In phase 3, data evaluation, the accumulated data is evaluated and categorized (Fig. 9). Visual inspection is performed to assess the quality level of the weld with the different welding parameters and to categorize the welds in terms of ISO 5817 [35]. The welds are

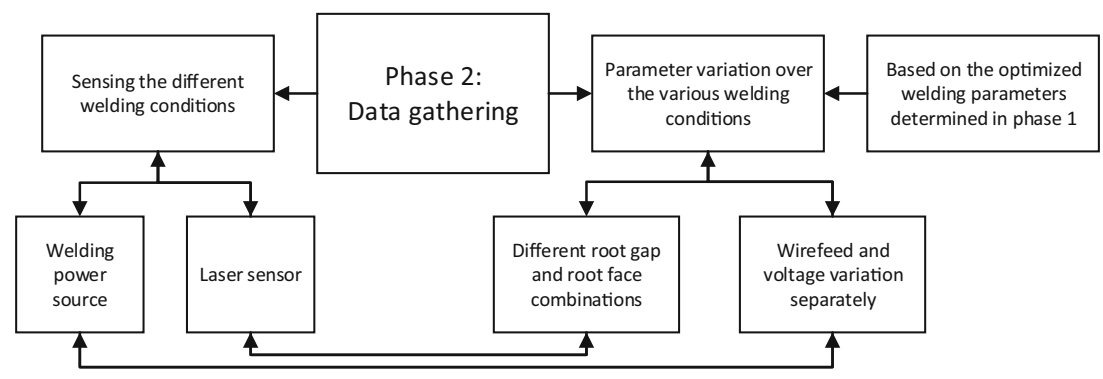


Fig. 8 Training process of the ANN and creation of the knowledge bank

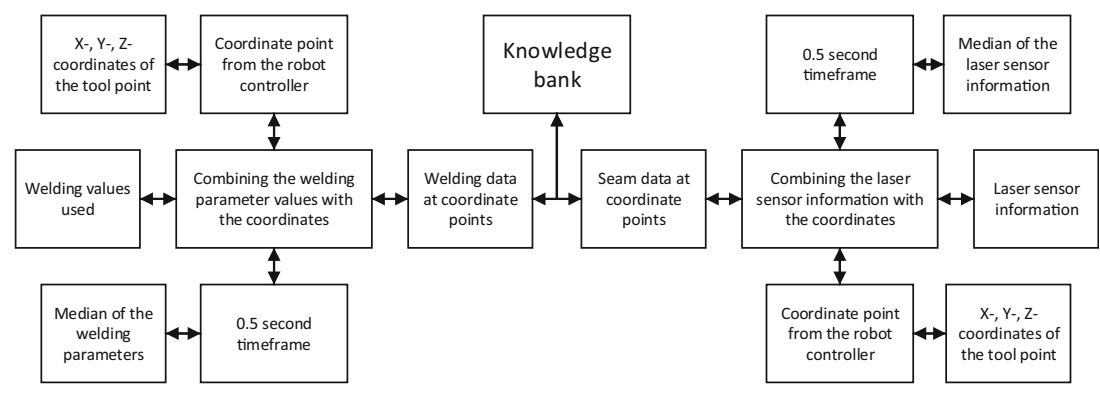

categorized as acceptable and unacceptable sections, with quality level $\mathrm{B}$ being the quality requirement. To reduce variation errors between the welding experiments and conditions, the categorization needs to be done for all of the welding experiments. Accurately defined welds are required to achieve consistent quality with the neural network system. It can be said that the more precisely the welds are categorized, the better the performance of the ANN decision-making system.

Phase 4:

The neural network was trained with the data collected in phase 2 and evaluated in phase 3. The different seam profiles combined with the evaluated welding parameter combinations were uploaded to the input-output pairs in the neural network's training process. Various hidden layer and neuron configurations were tested to overcome the overfitting problem [36, 37].

A backpropagation neural network with the LevenbergMarquardt algorithm was used as the basis for the ANN

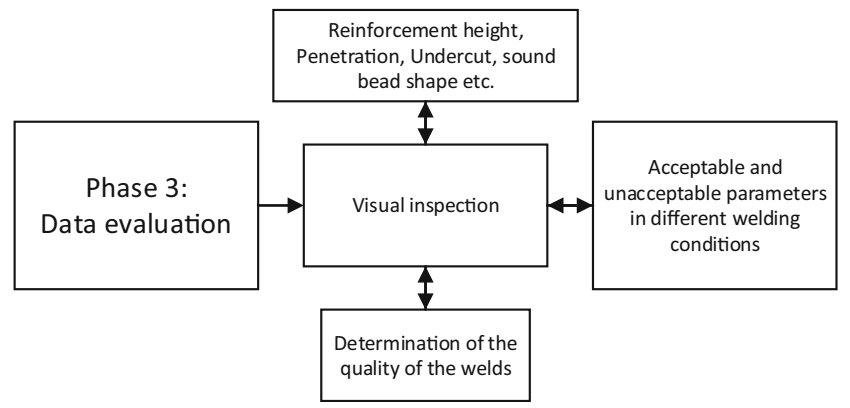

Fig. 9 Data evaluation phase of the welding experiments decision-making system. The system was trained with various network configurations to define the performance and adjustment accuracy of the network. The simulation was carried out by giving a wide range of variation in the root gap and root face data. The ANN decision-making solutions were simulated and plotted throughout the root gap and root face variation field. The purpose of the simulation is to evaluate the neural network decision with common sense to avoid inconsistency with the ANN-controlled welding experiments. Also, the common problem of overfitting of the network can be avoided effectively by simulating the results. Finally, the optimized neural network was trained with $70 \%$ training data, $15 \%$ testing, and $15 \%$ evaluation data.

After the simulation process was completed, welding experiments with the ANN decision-making control system were carried out. Varying root gap and root face were created by grinding the seam. The tack welds welded in the seam before scanning were ground to have a smooth connection, avoiding incomplete penetration at the start and end points of the tack weld.

The seam scanning data was used as the basis for the decision-making of the ANN control system. The system requests the robot position every $0.5 \mathrm{~s}$ and finds the closest coordinate measured on the seam profile. The ANN control system gathers the data from the seam information (root gap and root face) from the closest coordinate position and sets the welding parameters for the welding power source. The outline of the ANN training and welding experiments are shown in Fig. 10.

Three welding experiments were done with varying root gap and root face and different tack weld shapes and sizes to determine the decision-making accuracy of the trained neural network. The seam profile data and welding parameters were
Fig. 10 ANN training and implementation phase of the welding experiments

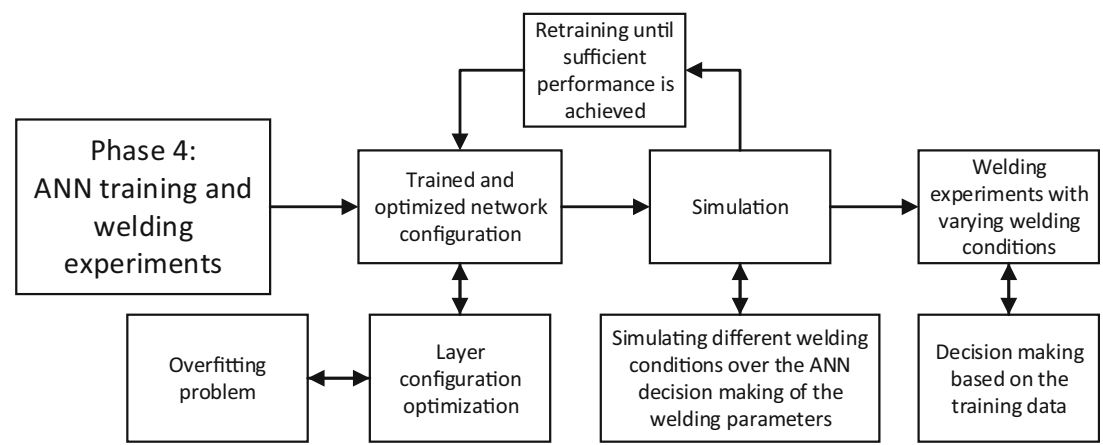


Fig. 11 Weld inspection phase 5 of the welding experiments

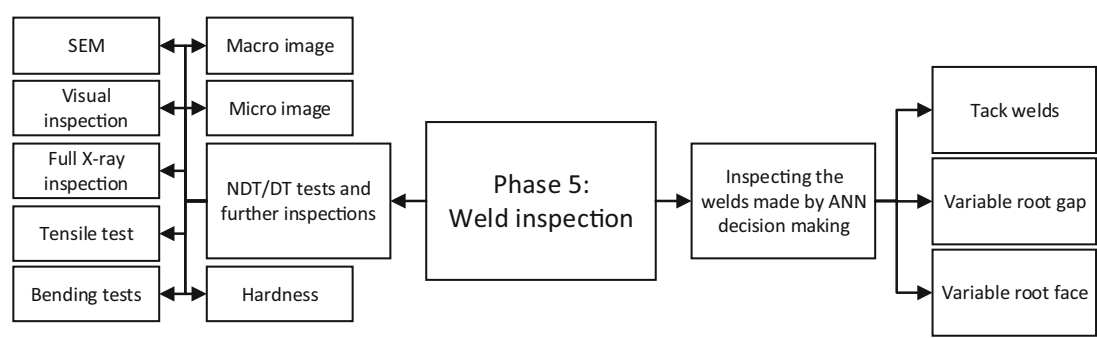

used for the evaluation along with welding procedure tests: microscopy, X-ray, SEM imaging, and hardness tests.

\section{Phase 5:}

In order to identify the quality of the welded joints, NDT and DT inspections were carried out. Figure 11 presents the weld inspection methods used in the study. Visual inspection was carried out to define the external quality and visual appearance of the weld. The internal quality was defined with Xray imaging, macro and micro images, and bending and tensile tests. To compare the properties of the weld joint, the tensile tests were carried out for both the normal section and the tack welded section. The experiments were evaluated and categorized by the quality levels of ISO 5817 [35]. Hardness tests (HV5) of the welded joint were carried out on the root pass and the surface pass of the weld. Additionally, microstructure and SEM analyses were done to study the material properties and HAZ characteristics.

\section{Results and analysis}

In this section, the results of the study are presented and analyzed. The focus of analysis is on the first pass welded with the
ANN control system. First, the results of the ANN training process are introduced. Next, the root passes of the three welded experiments are presented, followed by a discussion of the experiments and parameter adjustment accuracy of the ANN. Finally, the quality aspects of the welded experiments are discussed and evaluated.

\subsection{ANN training process}

ANN training data was gathered from 20 training specimens each of $300 \mathrm{~mm}$ length. Specimen seam surfaces were ground before welding to have inconsistent root face and root gap. The specimens were welded with constant values, and they were evaluated after welding according to ISO 5817. A welding engineer assessed the welds, and training data was collected from the individual measurement points at the assessed lengths of weld. The training data was then categorized in weld quality levels of B and not accepted parts. The accepted training data was combined in one data in Fig. 12 consisting of 1477 samples for neural network training and validation. Each sample number of the dataset consists of both input and output parameters for neural network training.

The neural network was trained based on the dataset in Fig. 12 by using the root face and root gap as input parameters and wire feed and arc voltage correction as output parameters.
Fig. 12 Dataset of the neural network training

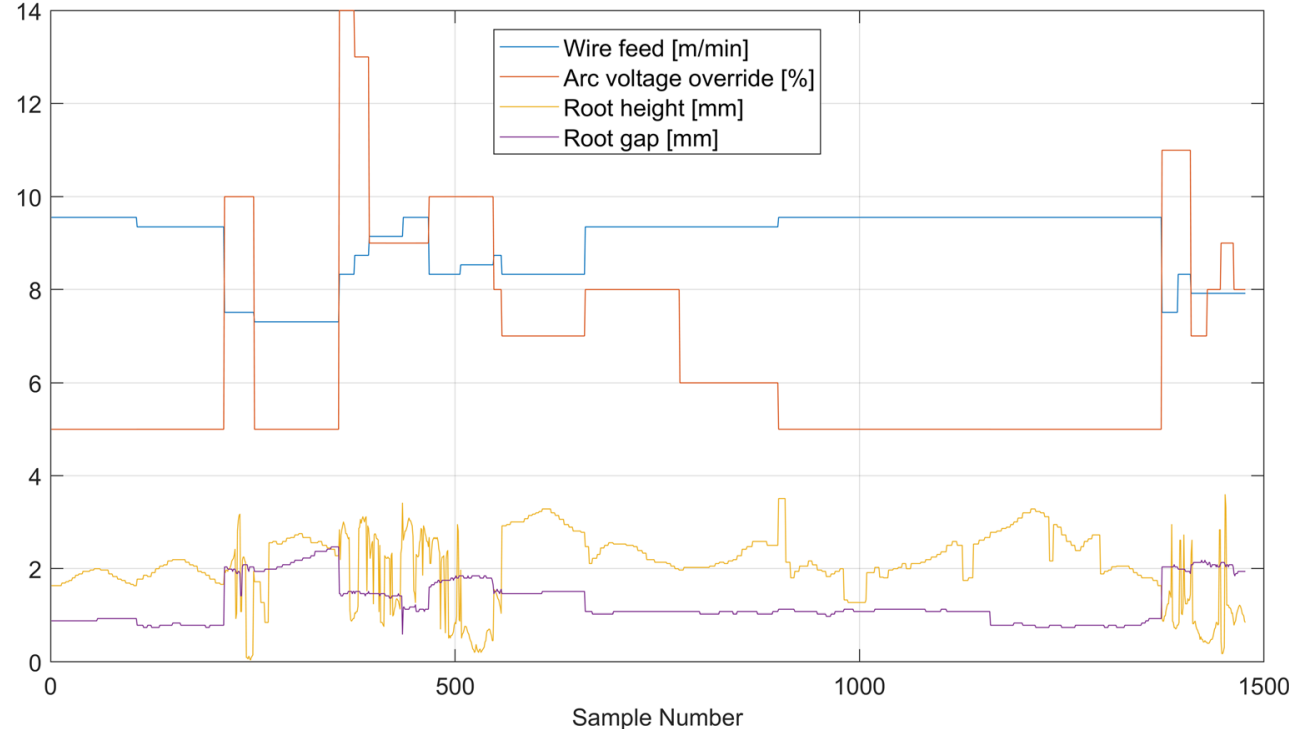




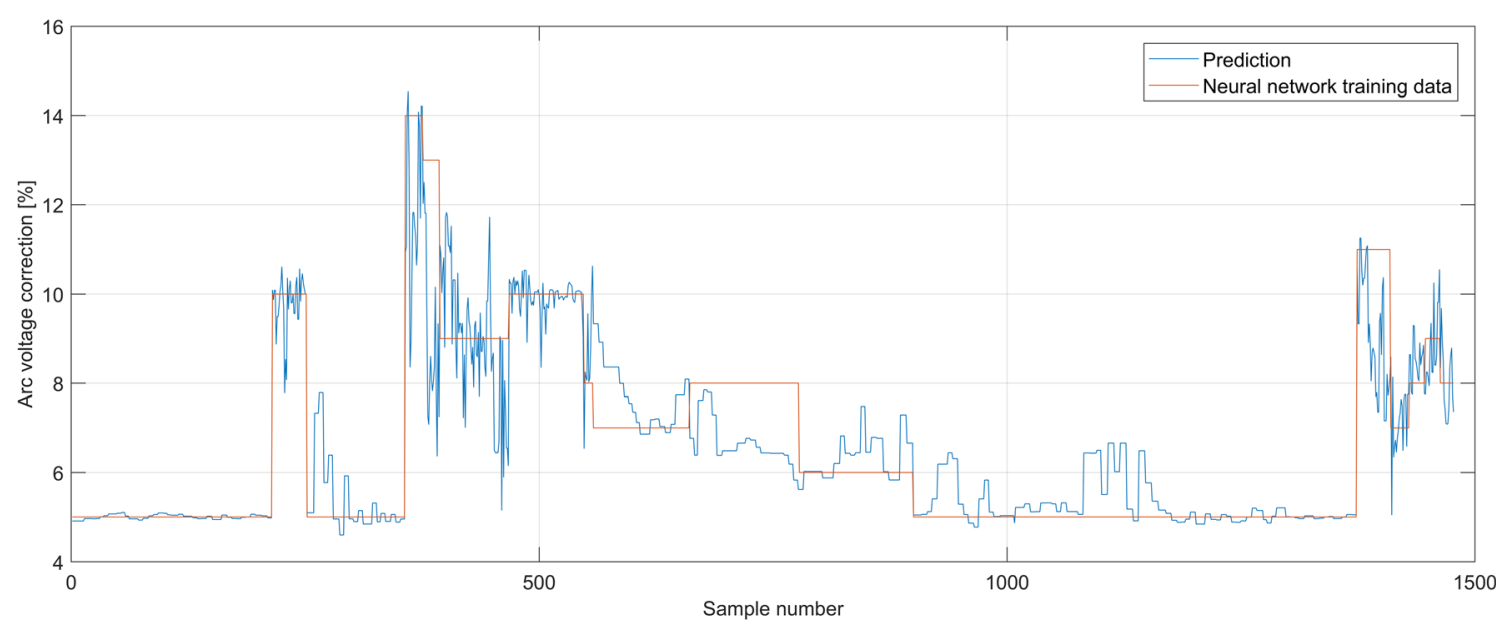

Fig. 13 Arc voltage prediction compared to neural networks training data

Training function used was a Levenberg-Marquardt backpropagation with layer configuration 2-20-20-2 (2 layers, both consisting 20 nodes). The Levenberg-Marquardt method was chosen because of the suitable prediction accuracy and light computing requirement. The training data process consists of $70 \%$ training, $15 \%$ validation, and $15 \%$ of testing data which are divided into three sets using random indices. The performance function for the case was chosen to be MSE (mean squared error), while the network input function was the net sum, activation function was rectifier activation function, the learning rate was 0.01 , momentum was 0.9 , and batch size was 64 . The training validation performance for the network was 0.8611 , while the training performance was 0.6277 and test performance was 0.8503 for the trained network. The network performance was obtained with 29 iterations.

After the network training, the network's prediction versus neural networks training data, presented in Fig. 12, was compared (Figs. 13 and 14). It can be seen that there is some dispersion compared to the neural networks training data; however, the overall response to the swift changes in both arc voltage and power is reasonable. The dispersion of the data can be explained with the training data, where some sensor data errors might have occurred caused by spatters, dust, and reflections in the workpiece.

Although the anomalies cause inconsistency and dispersion in simulation, the effect of a single prediction to weld output is not significant as the welding parameter adjustment is done with a median of five samples. Figures 15 and 16 show the absolute error in both arc voltage and power in percentage compared to the neural network training data. As shown in Figs. 17 and 18, the dispersion of the data is drastically decreased with a median of five samples as it is used in actual performance evaluation of the system. The mean absolute error was $0.5560 \%$ with power prediction error and $0.9044 \%$ with arc voltage error. Typical parameter window determined for the welding procedure specifications (WPS) in this material group (1.2) is $\pm 10 \%$. Thus, the prediction did not exceed the specification limits; it can be determined to have reasonable accuracy to reach the preferred quality consistency in actual applications based on the simulation evaluation.

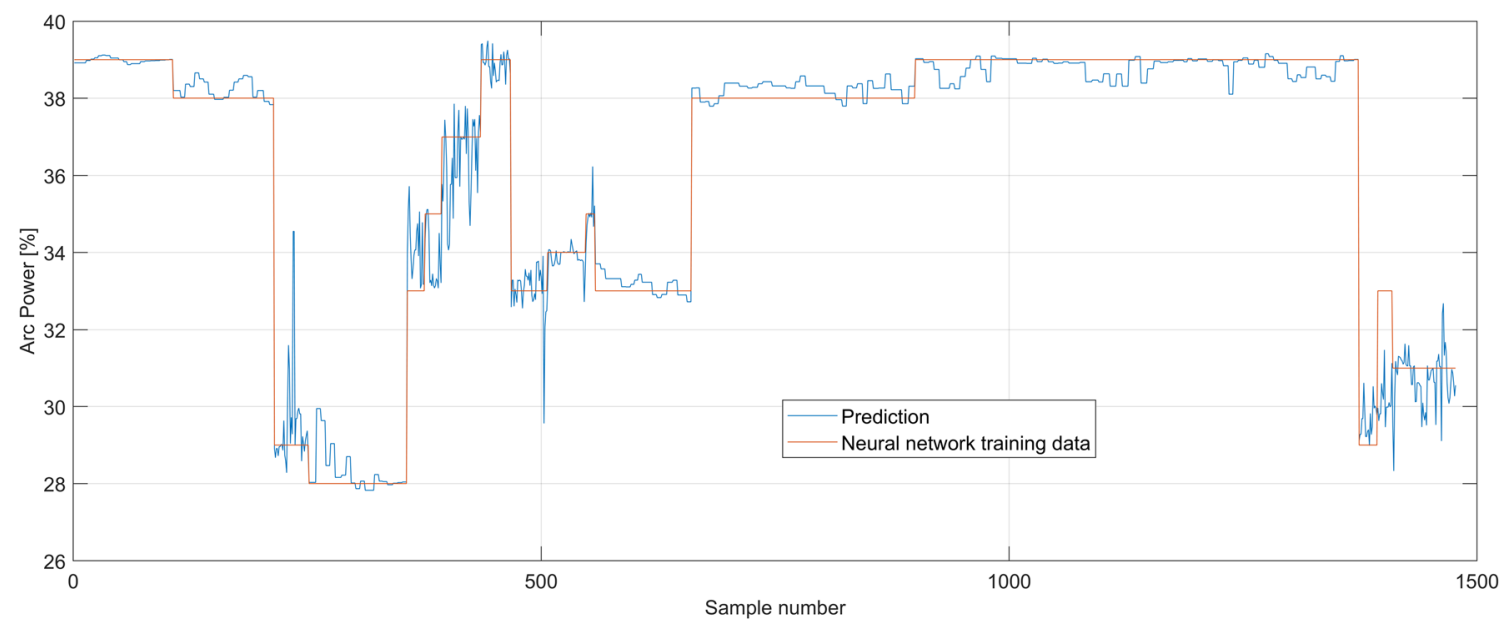

Fig. 14 Arc power prediction compared to neural networks training data 


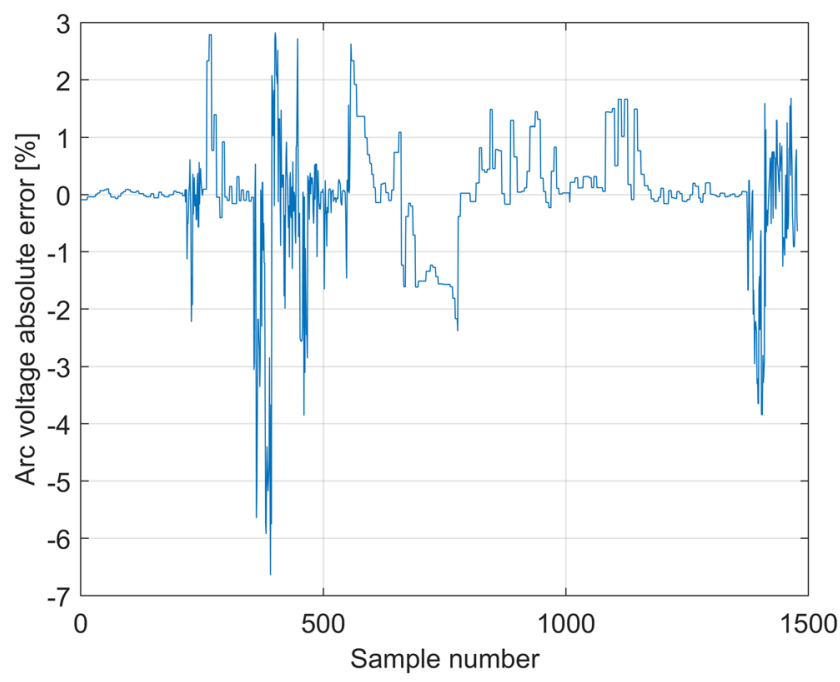

Fig. 15 Arc voltage absolute error compared to neural networks training data

The ANN was trained with data from the data gathering phase (phase 2). To define the approximate accuracy and prevent overfitting of the neural network, simulation of the ANN decision-making system was done with multiple layer configurations. Based on the simulation results, an optimized layer configuration of 2-20-20-2 was chosen for the ANN decisionmaking system. The simulated solutions over varying root face and root gap of the selected layer configuration are presented in Figs. 19 and 20.

\subsection{Root pass with the ANN control system}

Three experiments (A, B, C) were done with varying root gap, root face, and tack weld shapes and sizes. The experiments represent conditions similar to normal production environments. Root gap ranged from 0.7 to $2.2 \mathrm{~mm}$ and root face from 0.9 to $2.6 \mathrm{~mm}$; otherwise, the groove geometry remained

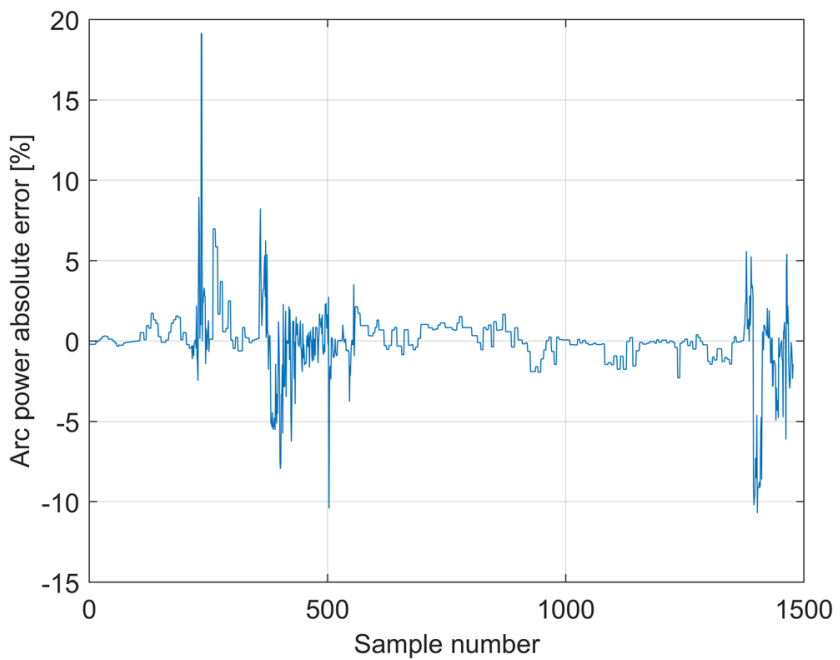

Fig. 16 Arc power absolute error compared to neural networks training data

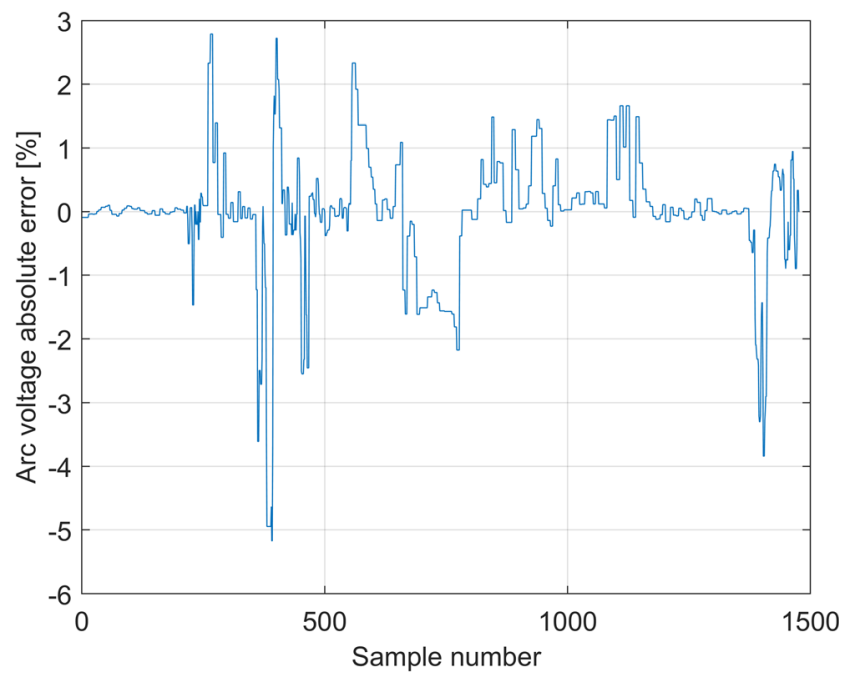

Fig. 17 Actual performance error of the arc voltage after median filtering

constant. The first pass was controlled by the neural network; hence, it is analyzed in more detail. Buildup passes are evaluated collectively as they are welded with constant values.

\subsection{Experiment A}

In experiment $\mathrm{A}$, the seam profile and tack weld images had high contrast and were distinct. The darker the color in the image, the further the reflection occurred (Fig. 21). The image provides sufficient accuracy for root gap and root face measurement. Vertical line marks (caused by machining and the grinding operation) in the groove do not decrease the measurement accuracy and evaluation of the seam. The measurements of the root gap and root face of the seam can be found in Fig. 23.

The root gap varied from 1.3 to $2.2 \mathrm{~mm}$, and the root face varied between 0.9 to $2 \mathrm{~mm}$ across the welded area. The welding process was stable and without spatter (Fig. 22). The quality of the weld was verified with X-ray imaging,

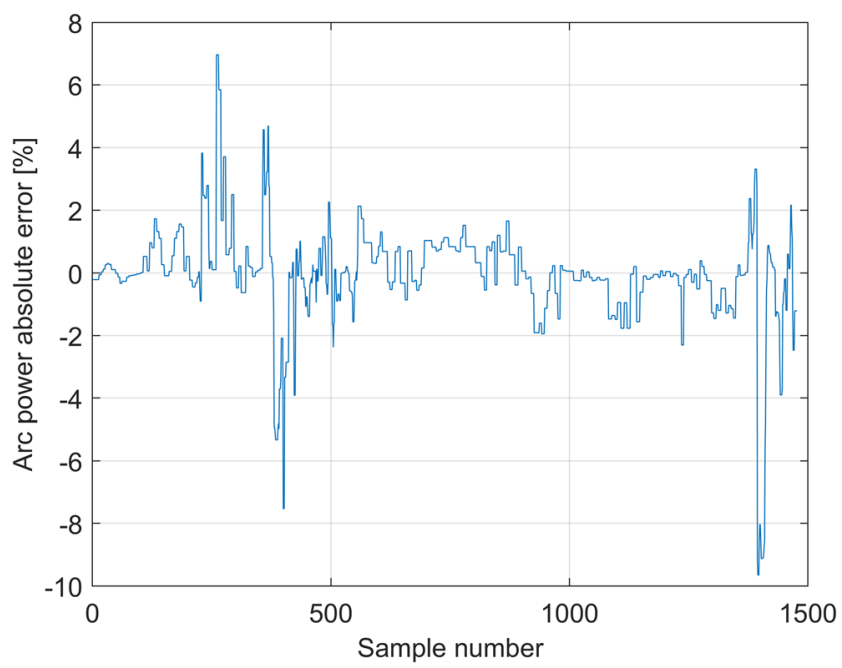

Fig. 18 Actual performance error of the arc power after median filtering 


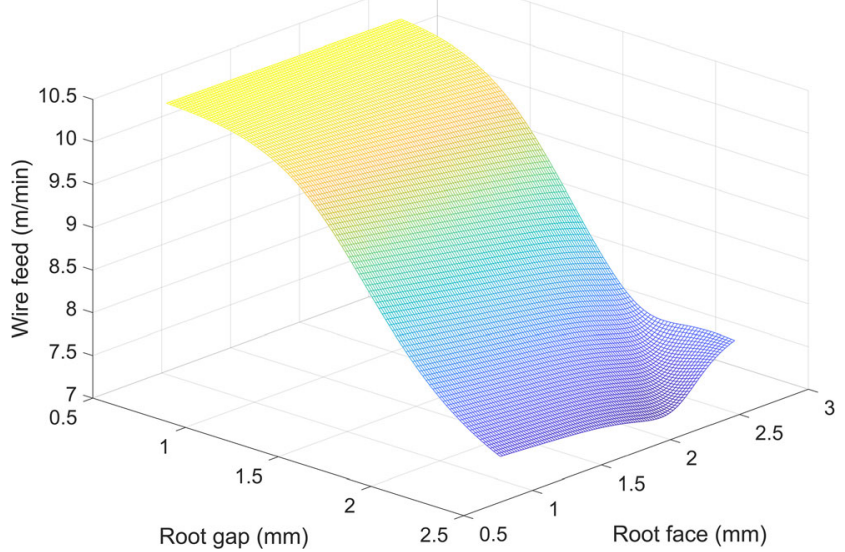

Fig. 19 Wire feed solution of the ANN decision-making system

which showed a smooth connection with base metal and only minor imperfections in the weld metal. The parameter variations over experiment A can be seen in Fig. 23. The vertical seams on the back side of the weld are the connecting welds of the sheet related to the manufacturing process, which is not made by the ANN-based system and is not part of the evaluation.

The tack weld of experiment A was positioned in the 130to $160-\mathrm{mm}$ position in the weld. The tack weld was recognized by the root gap dropped to zero and root face (height of the tack weld) rose. From the wire feed and arc length figures (Fig. 23), it can be noted that tack weld was controlled by raising the arc voltage and reducing the wire feed. The root side of the weld was consistent with the penetration and no noticeable spores were formed (Fig. 22).

From 0 to $15 \mathrm{~mm}$, the root gap was constant, and the root face decreased from 2 to $1 \mathrm{~mm}$. The neural network reacted to the variation by decreasing the wire feed to reduce the arc pressure and penetrating effect. From 15 to $95 \mathrm{~mm}$, the root gap increased from 1.5 to $2.1 \mathrm{~mm}$, whereas the root face remained constant. To reduce the

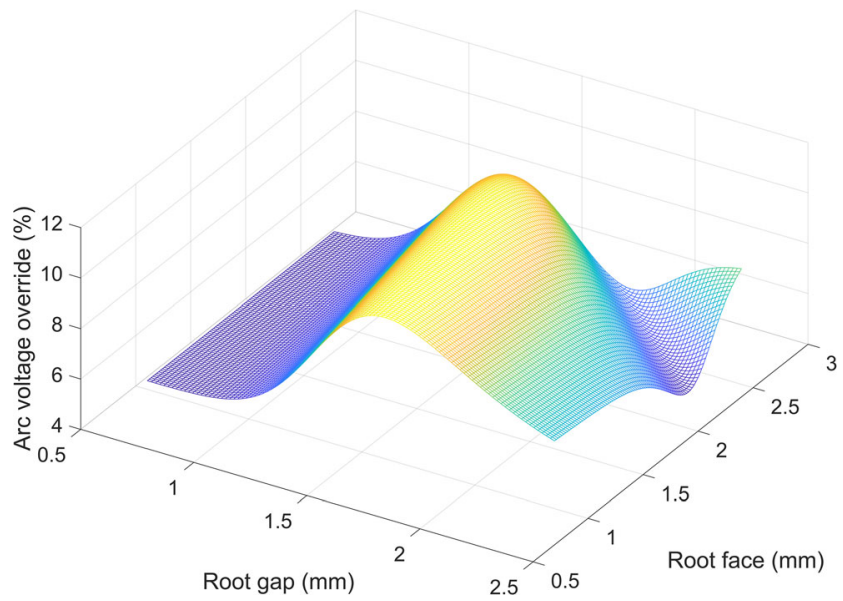

Fig. 20 Arc voltage override solution of the ANN decision-making system arc pressure, the ANN system reacted by reducing both wire feed and voltage. Just before the tack weld (95 to $130 \mathrm{~mm}$ ), the root gap decreased to $1.7 \mathrm{~mm}$ while the root face remained constant. To increase the arc pressure and penetration, the neural network increased wire feed to compensate for the variation in root gap. After the tack weld (160 to $180 \mathrm{~mm}$ ), both the root gap and root face remained constant, which resulted in a constant welding parameter decision of the ANN control system.

It can be noted that the heat input is related to the variation of the root gap and root face. At the beginning of the weld, the heat input was $0.7 \mathrm{~kJ} / \mathrm{mm}$ (root gap $1.3 \mathrm{~mm}$, root face $2 \mathrm{~mm}$ ) and for wider root gap conditions, at around $80 \mathrm{~mm}$, the heat input was $0.57 \mathrm{~kJ} / \mathrm{mm}$ (root gap $2 \mathrm{~mm}$, root face $1 \mathrm{~mm}$ ). The penetration of the welded seam remained constant throughout the weld, which indicates accurate decision-making by the ANN system.

\subsection{Experiment B}

Experiment B represented a narrow root gap $(0.7 \mathrm{~mm}$ to $1.3 \mathrm{~mm}$ ) while the root face varied from 1.4 to $2.7 \mathrm{~mm}$. The imaging of the seam is slightly blurry and inconsistent because of anomalies in the groove surface (Fig. 24). The measurements of the root gap and root face of the seam can be found in Figs. 25 and 26.

Anomalies affected the visual image of the seam remarkably, although the effect on measurement evaluation was minor. The root gap width sensing gave accurate measurements, whereas the root face measurement was slightly inconsistent. It can be noted that the root gap measurement contrast drops as the width of the root gap reduce, making an evaluation process of the seam more challenging. The issue of this phenomena is described more in the previous study of Ratava et al. [34]. Figure 26 shows that the neural network increased the wire feed from 0 to $20 \mathrm{~mm}$ welding distance when the root gap decreased, and the root face increased. The wire feed was decreased from 20 to $30 \mathrm{~mm}$ welding distance when the root gap reduced. The neural network reacted to root gap reduction by increasing the arc length. At the same time, the heat input remained constant. From 30 to $100 \mathrm{~mm}$, the wire feed was not drastically changed as the root gap and root face remained relatively stable. It can be noted that to increase the penetration, the neural network increased the wire feed when the root face increased.

The heat input was relatively consistent after $20 \mathrm{~mm}$ of welding. The heat input increased $(0.6$ to $0.7 \mathrm{~kJ} / \mathrm{mm})$ from 0 to $20 \mathrm{~mm}$ welding distance, after which the values remained relatively constant at around $0.7 \mathrm{~kJ} /$ $\mathrm{mm}$. The penetration and quality of the weld were consistent throughout the weld (Fig. 25b, c). 
Fig. 21 Seam profile of experiment $\mathrm{A}$ evaluated by the laser intensity of the reflected laser

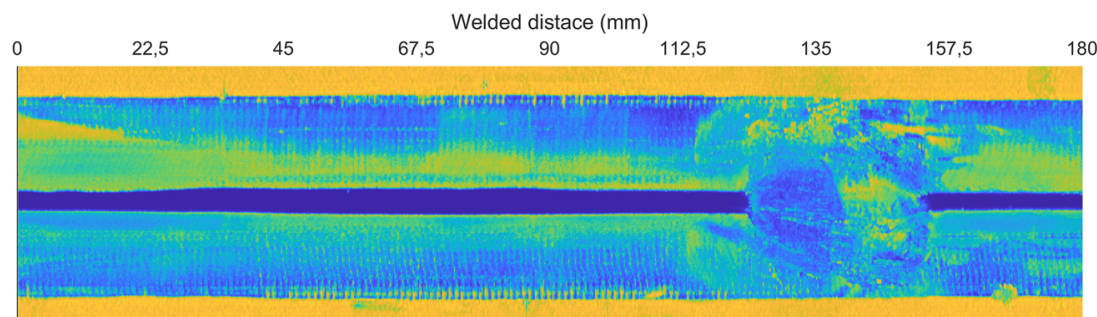

\subsection{Experiment C}

Experiment $\mathrm{C}$ represented a response to the tack weld and changing welding conditions of root gap from 1.1 to $1.7 \mathrm{~mm}$ and root face from 1.4 to $2.1 \mathrm{~mm}$. The visual seam profile showed an accurate measurement of the workpiece (Fig. 27), although some anomalies caused by grinding can be seen in the tack welded area. The measurements of the root gap and root face of the seam can be found in Fig. 29.

The tack weld was welded at the distance of 15 to $38 \mathrm{~mm}$ from the beginning of the weld. At $10 \mathrm{~mm}$ position, the root face increased rapidly to $3.5 \mathrm{~mm}$ just before the tack weld (Fig. 29). The variation can be explained by spattering caused by the tack welding and grinding grooves from the preparation work. The anomalies can be seen in the left-hand corner of Fig. 27 (both sides of the groove) before and after the tack weld. The ANN responded to anomalies by increasing the wire feed (to increase the arc pressure), which can be seen at 40 to $45 \mathrm{~mm}$. The effects of the anomalies can be seen in the root penetration (Fig. 28b, c); root penetration increased but remained within acceptable levels.

As analyzed from the seam profile image (Fig. 27), the welding parameters and heat input (Fig. 29) relate to the sensed seam. From 45 to $140 \mathrm{~mm}$ welding distance, the welding parameters did not vary greatly because of the consistent welding conditions. When the root face decreased from 2 to $1.4 \mathrm{~mm}$ ( 70 to $110 \mathrm{~mm}$ welding distance) the voltage was decreased to reduce the risk of burn through. At the end of the weld (120 to $150 \mathrm{~mm}$ welding distance), the root penetration bead increased slightly when the ANN control system increased the arc voltage by $1 \mathrm{~V}$ and current by $10 \mathrm{~A}$. The

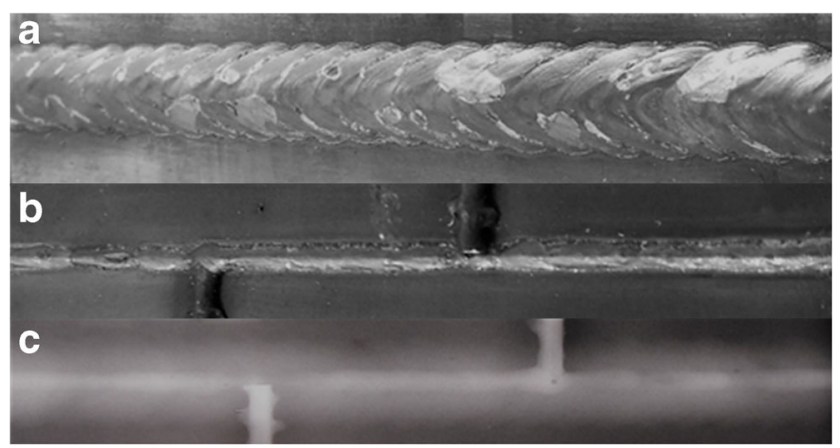

Fig. 22 Visual images of experiment A. a Surface. b Root. c X-ray adjustment increased the penetrating effect to overcome the effect of increased root face. In practice, the root face was constant at that point, which led to increased root penetration. However, the quality of the weld still remained at an acceptable level. The heat input increased momentarily just before $(15 \mathrm{~mm})$ and after $(45 \mathrm{~mm})$ the tack weld because of the measurement errors. From 50 to $120 \mathrm{~mm}$ the heat input remained relatively constant. From 120 to $140 \mathrm{~mm}$, the same effect of the sensing error can also be seen in the heat input figure as raised values of current and voltage.

\subsection{Buildup welds and final pass}

The second, third, and fourth passes were welded on top of the previous passes, without cleaning, with an interpass temperature of $185^{\circ} \mathrm{C}$. Some slag formed on top of each pass but the slag was melted by the arc energy without leaving any defects. The slag formed from the melting filler wire and consisted of a mixture of silicon dioxides and metal oxides.

The second pass was welded with wire feed of $9.0 \mathrm{~m} / \mathrm{min}$ $(220 \mathrm{~A})$, arc voltage of $25.9 \mathrm{~V}$, and welding speed of $5 \mathrm{~mm} / \mathrm{s}$ with a heat input of $0.91 \mathrm{~kJ} / \mathrm{mm}$. The formed bead was even and connection to the base metal was smooth, creating acceptable conditions for welding the next pass.

The third pass was welded with wire feed of $9.4 \mathrm{~m} / \mathrm{min}$ (220 A), arc voltage of $29.6 \mathrm{~V}$, and welding speed of $4 \mathrm{~mm} / \mathrm{s}$ with a heat input of $1.30 \mathrm{~kJ} / \mathrm{mm}$. The arc voltage was raised to widen the arc, so the base metal is melted over a wider area, as the $\mathrm{V}$-groove requires a wider area to melt both edges of the weld. In addition to increased arc voltage, torch weaving was used to assure sufficient melting of the base material.

The fourth pass was welded with wire feed of $10.0 \mathrm{~m} / \mathrm{min}$ (230 A), arc voltage of $29.6 \mathrm{~V}$, and welding speed of $5 \mathrm{~mm} / \mathrm{s}$ with a heat input of $1.09 \mathrm{~kJ} / \mathrm{mm}$. In the fourth pass, the torch weaving was widened to ensure complete melting of the edges of the previous weld. Moreover, wider torch weaving results in smoother and lower reinforcement height of the bead (Table 2).

\subsection{Outcome of the experiments}

In conclusion, it can be noted that the ANN decision-making system adapted closely to the varying welding conditions. A few misreadings occurred with the machine vision system, but 

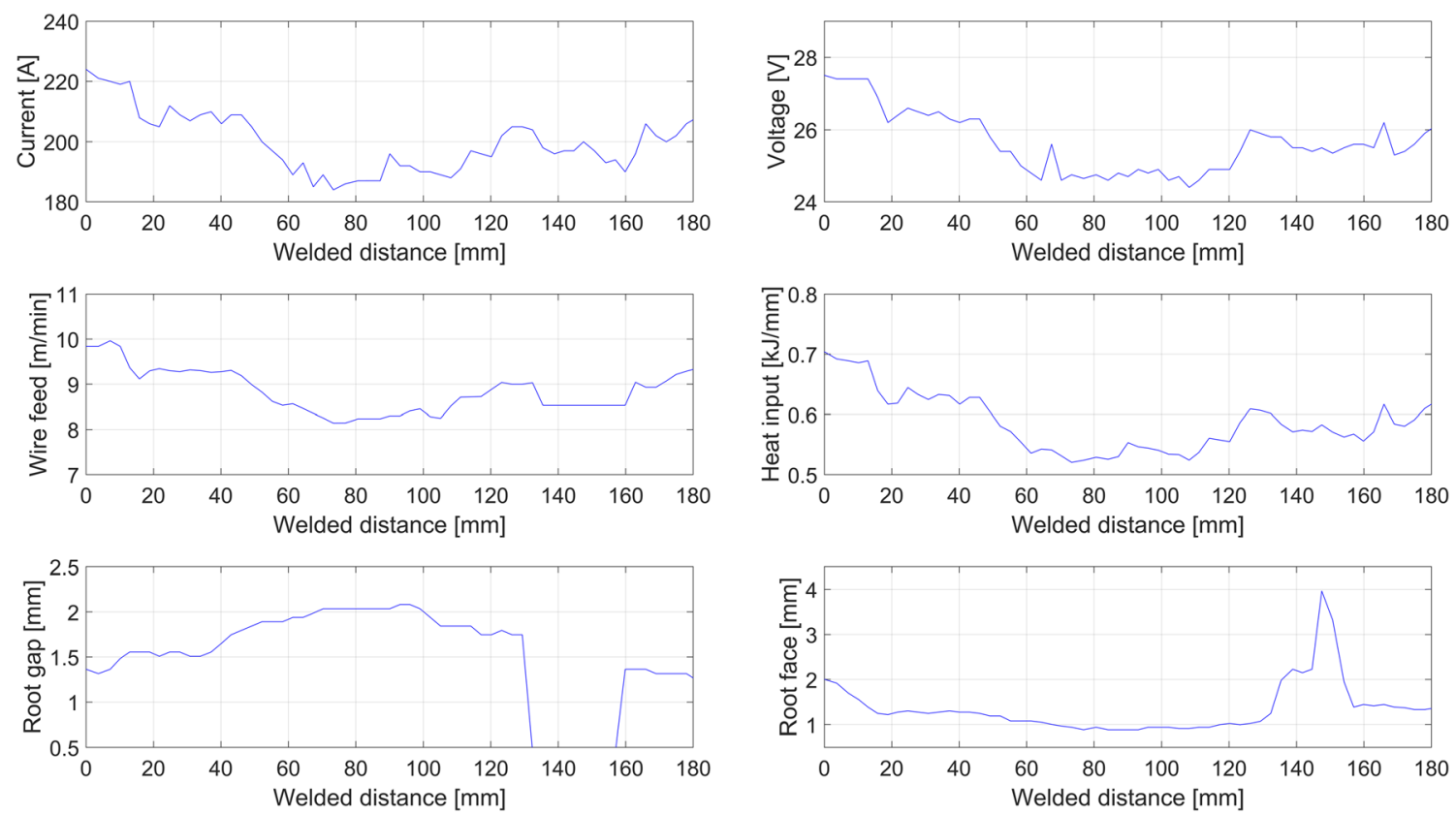

Fig. 23 Weld parameters and conditions of experiment A plotted over the distance welded

Fig. 24 Seam profile of experiment B evaluated by the laser intensity of the reflected laser

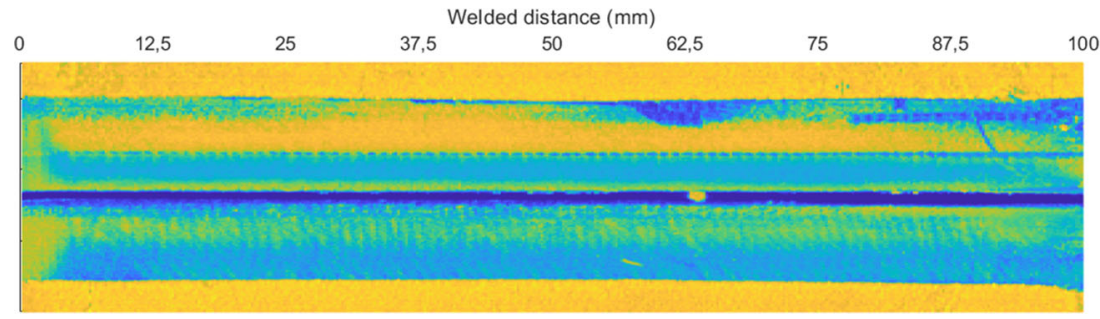

the effects of the misreadings were not significant as the system filters the input data as a median of the last three measurements. The incorrect measurements occurred mainly because of grinding of the tack welds, which disturbed the root face measurement of the seam by reflecting the laser and thus creating anomalies in the seam profile data. The analysis software

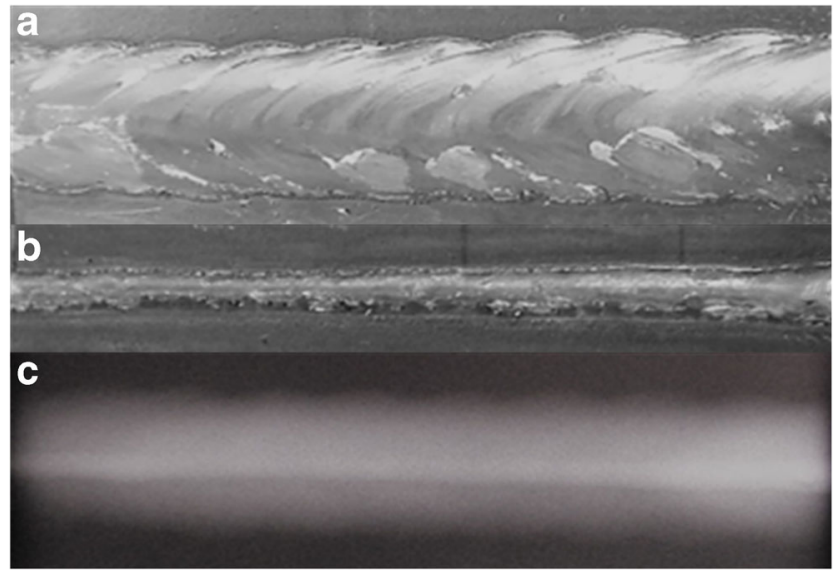

Fig. 25 Visual images of experiment B. a Surface. b Root. c X-ray sensed the reflection as an edge of the groove just next to the root gap, resulting in an estimation of an increased root face (based on Figs. 27 and 29). With the correctly measured groove, the decision-making system sensed the positions shapes and sizes of the tack weld and adapted to the conditions accordingly. Based on Figs. 23, 26, and 29, there is a clear trend that the wire feed and arc voltage is increased (increased heat input) when the root gap reduces or the root face increases. Correspondingly, the wire feed and arc voltage are decreased (decreased heat input) in the case of an increased root gap or decreased root face. Overall, the welding process was stable and the bead shape was smooth with a good connection to the base metal.

\subsection{Quality}

In this section, the quality of the welded experiments is evaluated and categorized by the quality levels of ISO 5817 [35]. First, the quality of the weld is evaluated by NDT and DT, i.e., tensile tests, bending tests, and X-ray imaging. Next, the quality of the welds is evaluated with macrographic images, 

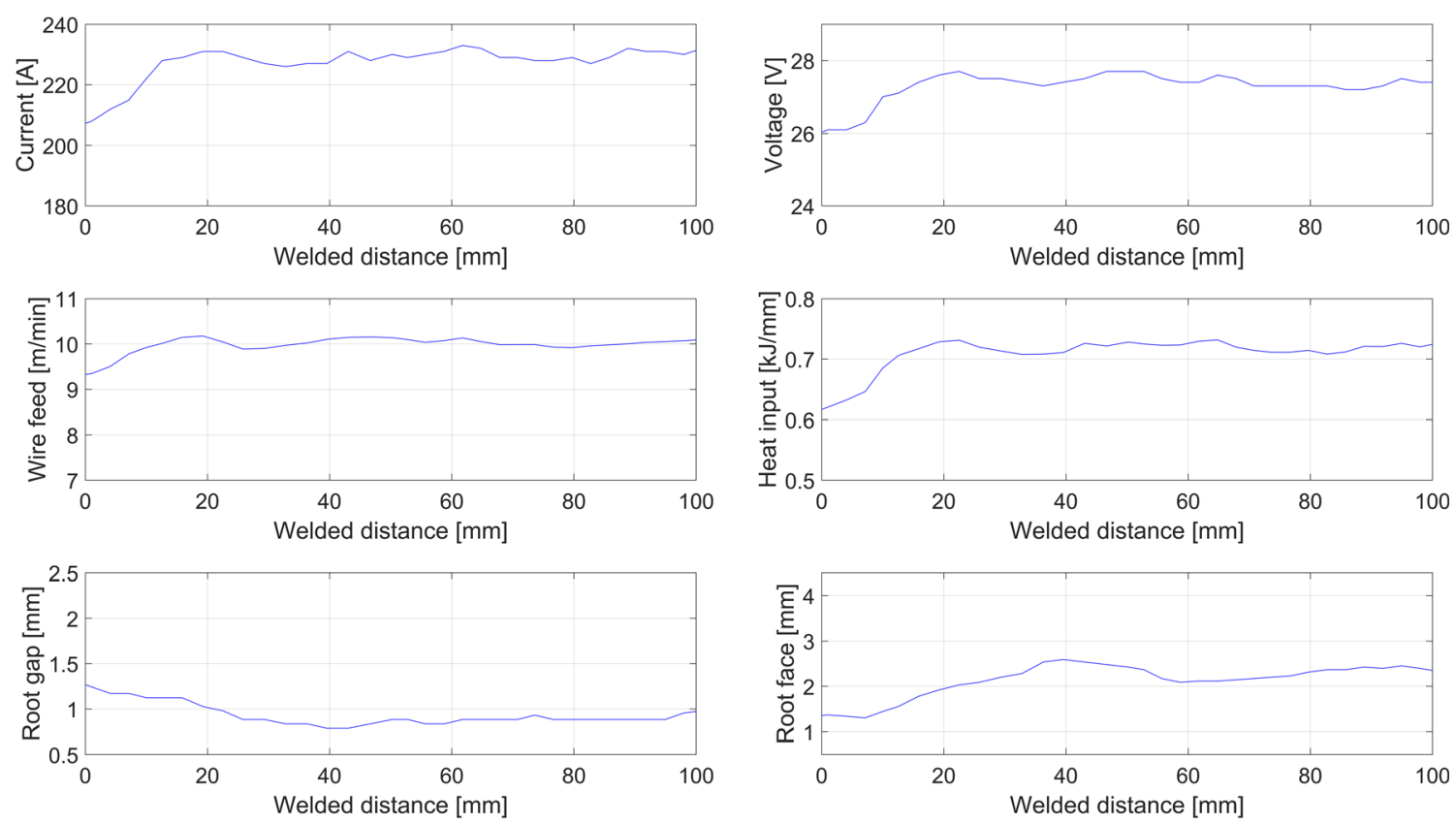

Fig. 26 Weld parameters and conditions of experiment B plotted over the distance welded

Fig. 27 Seam profile of experiment $\mathrm{C}$ evaluated by laser intensity of the reflected laser

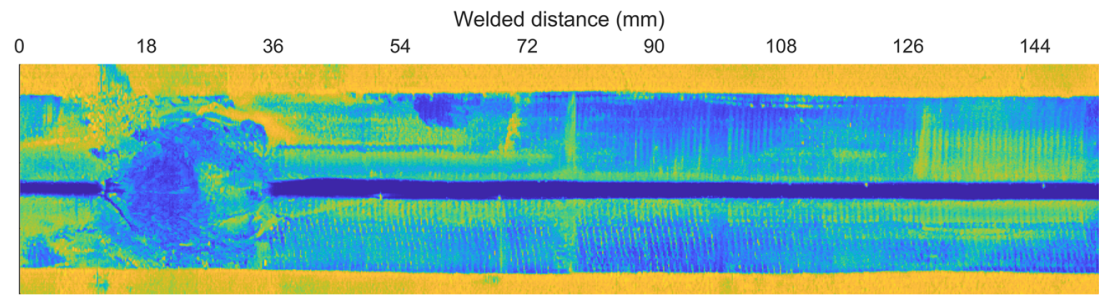

followed by hardness evaluation. Then, the microstructure of the weld and HAZ are evaluated with micrography. Finally, the coarse grain zone and the fusion line are evaluated with the SEM imaging.

The quality of the weld was assured with welding procedure tests, macrographic images, SEM imaging, and hardness tests. Tensile strength tests included testing of both the normal section and tack-welded section of the weld. The tensile

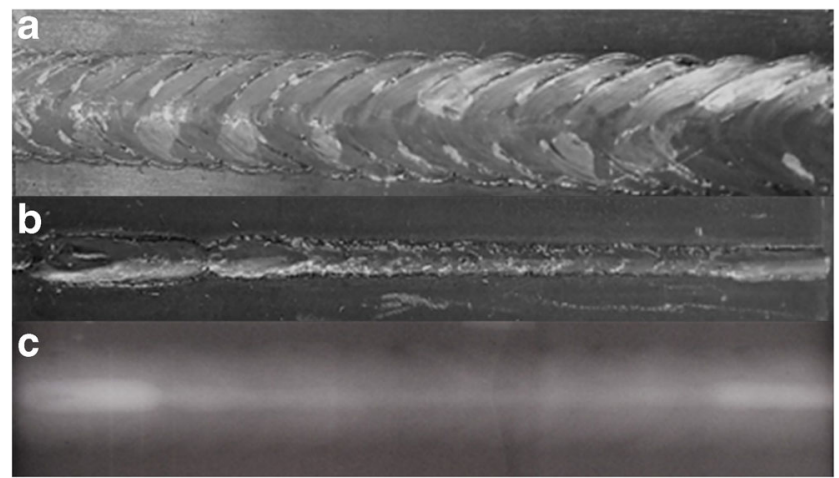

Fig. 28 Visual images of experiment C. a Surface. b Root. c X-ray strength of the normal section achieved $570 \mathrm{MPa}$ with elongation of $19.6 \%$, while the tack-welded section reached $545 \mathrm{MPa}$ with elongation of $19.7 \%$ (tensile strength variation of the base material according to the manufacturer is 480 to $620 \mathrm{MPa}$ ). No noticeable cracks in the weld zone or base metal were found in surface and root side bending tests.

A macrograph of the weld is shown in Fig. 30. The connection to the base metal is smooth on both the surface and root side. The weld has no defects, porosity, or issues with lack of fusion. The bead shape is slight to the right-hand side of the image, which is caused by torch position variation in torch weaving. In both the third and fourth pass, the torch happened to be on the right-hand side of the seam at the specific point where the macro image was taken. The weld bead height is $1.98 \mathrm{~mm}$ and root face is $0.92 \mathrm{~mm}$. The hardness tests were done on the surface and the root side of the weld (Fig. 30). The hardness values over the weld ranged from 180 to $220 \mathrm{HV}$. The relatively similar hardness in the different zones can be explained by the low alloy materials (low hardenability) used in the experiments and the relatively high interpass temperature, which slows down the cooling time of the material. 

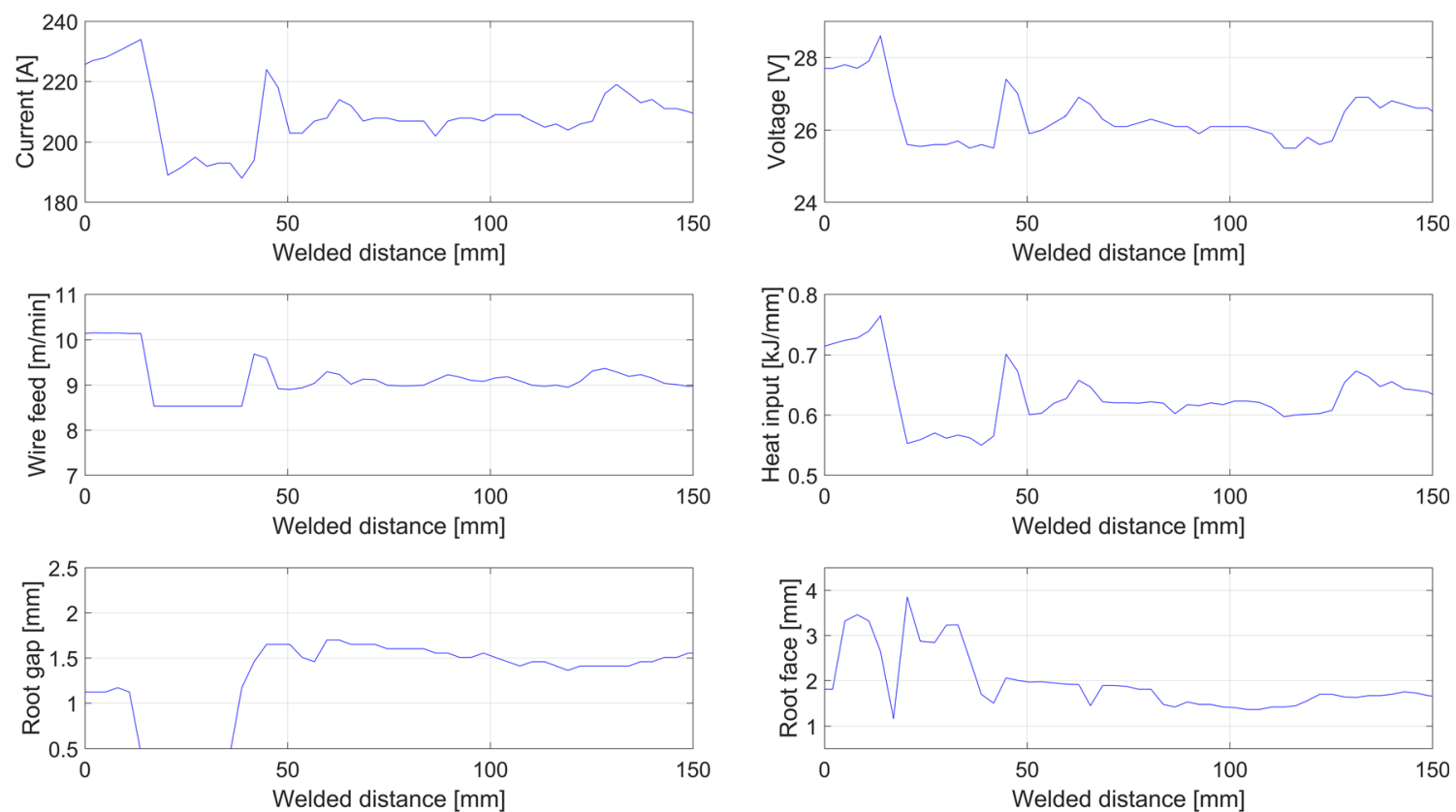

Fig. 29 Weld parameters and conditions of Experiment C plotted over the distance welded

Table 2 Buildup welds and final pass welding parameters

\begin{tabular}{lllll}
\hline $\begin{array}{l}\text { Welded } \\
\text { pass }\end{array}$ & $\begin{array}{l}\text { Wire feed } \\
{[\mathrm{m} / \mathrm{min}]}\end{array}$ & $\begin{array}{l}\text { Weld current } \\
{[\mathrm{A}]}\end{array}$ & $\begin{array}{l}\text { Arc voltage } \\
{[\mathrm{V}]}\end{array}$ & $\begin{array}{l}\text { Welding speed } \\
{[\mathrm{mm} / \mathrm{s}]}\end{array}$ \\
\hline 2nd pass & 9.0 & 220 & 25.9 & 5 \\
3rd pass & 9.4 & 220 & 29.6 & 4 \\
4th pass & 10.0 & 230 & 29.6 & 5 \\
\hline
\end{tabular}

More detailed magnification of parts of the image in Fig. 30 (red boxes 1-6) are given in Fig. 31. Figure 31 a shows the base material. The structure of the base material is ferrite with pearlite in the grain boundaries. The material has not been affected greatly by temperature changes because the temperature did not reach $\mathrm{A}_{3}$ temperature. The grain size of the base material is ASTM 11.5 [38].

Figure $31 \mathrm{~b}$ shows the fine grain zone of the weld. The grain size is ASTM 12.5 [38]. Fine grains are formed when the temperature rises above the $\mathrm{A}_{3}$ limit. Partial grain refining has occurred where the grain size is inconsistent (left lower corner of the image). The hardness of the fine grain zone ranged from 180 to $185 \mathrm{HV}$ on both the root and surface side, which is slightly lower than the hardness of the base material.

Figure $31 \mathrm{c}$ shows the transformation zone between the fine grain zone and the coarse grain zone. Coarse grains are formed when the temperature rises above $1030{ }^{\circ} \mathrm{C}$ (homogenization temperature). The grain structure transforms from fine grain

Fig. 30 Hardness values of the root and surface of the weld

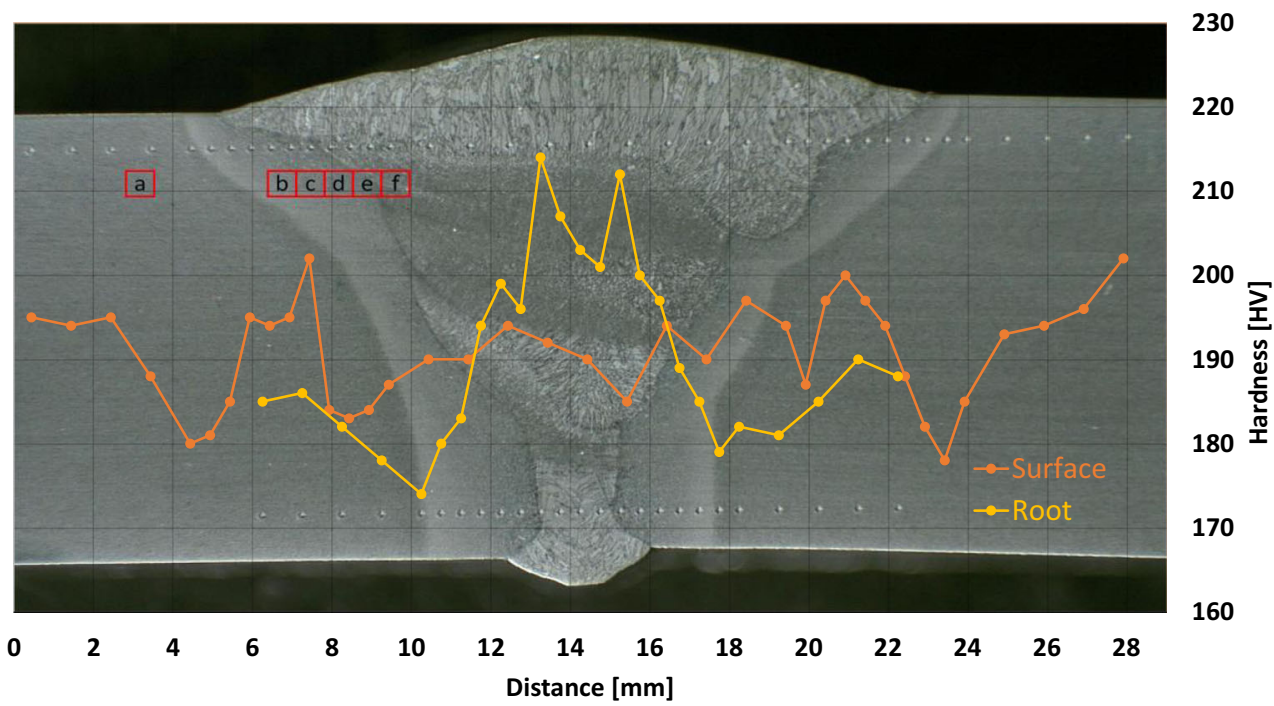




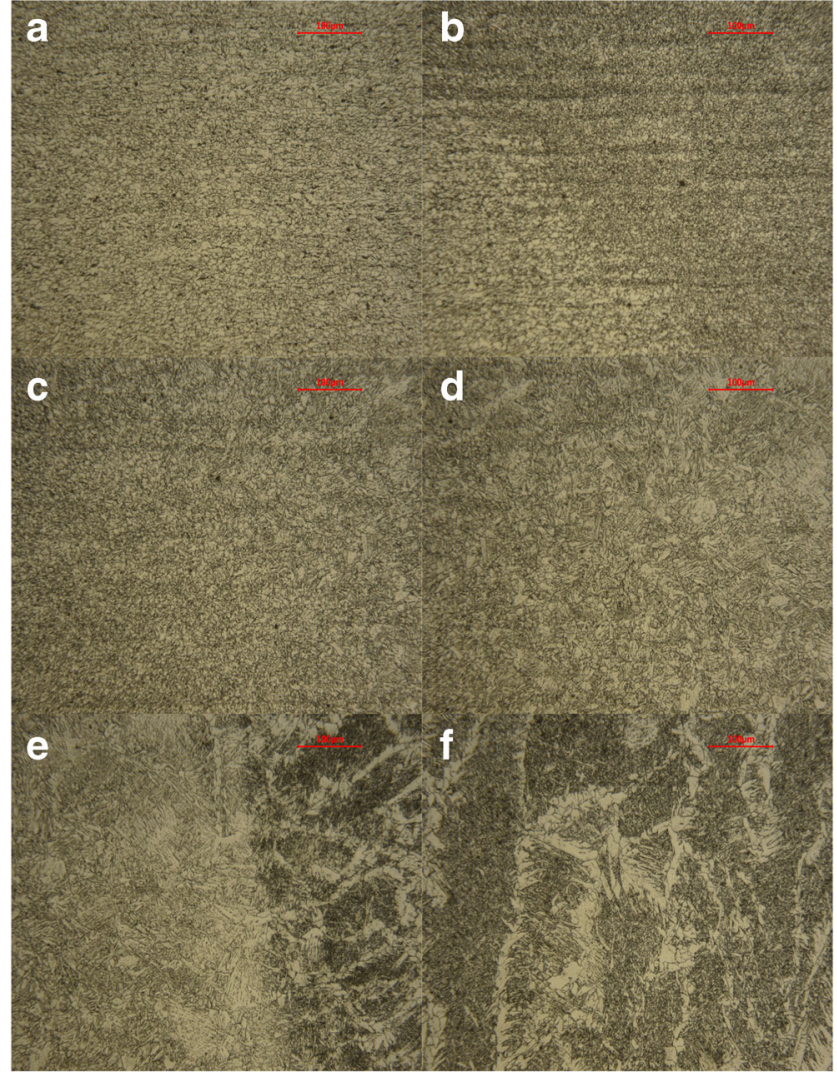

Fig. 31 Micrographs of the weld. a Base metal. b Fine grain zone. c Transformation zone. d Coarse grain zone. e Fusion line. f Weld material. acicular ferritic with pearlite to an acicular ferritic structure with bainite islands and pearlite in the grain boundaries. The hardness rises slightly as the bainitic content increases. Root side hardness increased from 180 to $190 \mathrm{HV}$ between the zones and on the surface side from 185 to $195 \mathrm{HV}$.

Figure $31 \mathrm{~d}$ shows the grain structure (ASTM grain size 9.0 [38]) of the coarse grain zone just before the fusion line. The grain structure is bainitic with pearlite islands and based on the surface hardness of $205 \mathrm{HV}$, the structure of the bainite is upper bainite.

Figure 31 e shows the fusion line of the weld. The composition of the material changes from ferritic-bainitic to a mix of acicular ferrite and pearlite with bainite islands, and hardness changes from 205 to $185 \mathrm{HV}$ on the surface side and from 190 to $215 \mathrm{HV}$ on the root side. The difference in hardness of the surface and root side can be explained by the cooling time differences of different passes. The first pass had faster cooling, resulting in a harder structure.

The micrographic composition of the weld material can be seen in Fig. 31f. The weld metal consists of Widmanstätten ferrite side plates in a fine grain acicular ferrite base. Also, some amount of bainite can be seen mixed with ferrite side plates (ASTM 10.5 [38]). The surface hardness of the weld metal is $195 \mathrm{HV}$ and root side hardness is $215 \mathrm{HV}$.

The grain structure of the coarse grain zone $500 \mu \mathrm{m}$ from the fusion line was verified by SEM imaging. Figure 32 shows SEM images of the workpiece. The red squares show the magnification area of the next image, ending at $\times 2000$ magnification of the HAZ coarse grain zone. It can be noted that

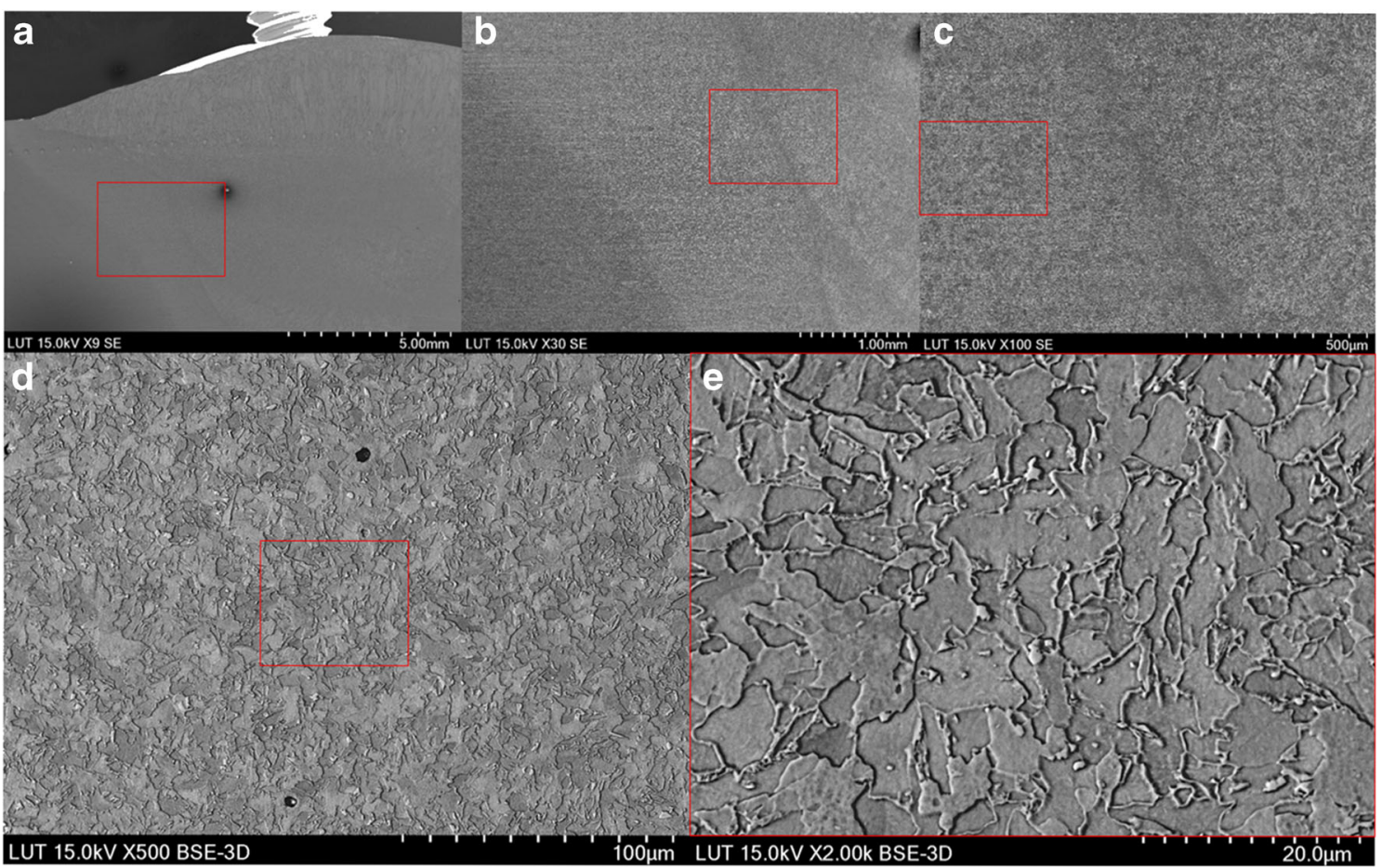

Fig. 32 SEM image of the workpiece with magnifications of $\times 9(\mathbf{a}), \times 30(\mathbf{b}), \times 100(\mathbf{c}), \times 500(\mathbf{d})$, and $\times 2000(\mathbf{e})$. Red boxes indicate the magnified area of the next image 
the grains are bainite islands (larger slightly stretched grains) in ferrite base with some pearlite. There are no segregation or ghost lines in the grain boundaries to weaken the structure.

\section{Discussion}

The first research question in this study is to determine the capability of a laser sensor to sense the weld seam and identify welding conditions automatically. The results of this study indicate that the sensing accuracy and resolution of the commercial laser sensor used is sufficient for precise seam measurement. The width of the root gap and the root face variations of different parts of the seam were sensed accurately and with relative ease, although imperfections of the seam can affect the quality of the measurement.

Measurement errors of the root face were found to cause inconsistency in the outcome of ANN decision-making. Although this experiment did not detect any evidence of a remarkable reduction in the quality of the weld, significant root face measurement error can lead to decreased or unacceptable weld quality. One unanticipated finding was that the lack of thermal profile sensor data did not reduce the quality of the weld. Furthermore, the quality was slightly more consistent than in the previous study [13], indicating that the welding process can be controlled with precision using laser sensor information only. The study indicates that the thermal sensor trailing the torch may reduce the quality of the weld in a rapidly changing welding environment, because of the measurement delay. Furthermore, in the previous study, the laser sensor's own analysis software was used to analyze the root gap which may affect the results of the weld quality.

An initial objective of the study was to determine the suitability and performance of the ANN controlled welding system for tack-welded butt welds with varying welding conditions. The welding process was adjusted based on the values of the root gap width and the root face. The generated knowledge bank ensured consistency in parameter adjustment, leading to weld consistent quality and penetration. It can be noted that the results provide support for the hypothesis that ANNbased control is suitable for butt welds produced with GMAW.

From the theoretical perspective, it is shown that with sufficient training data, the ANN control system can be used in practical GMAW applications and can assure constant quality and penetration without root support in varying welding conditions. Hence, the results broaden the application field of ANN control systems. In light of the results of this study and the previous study [13], it can be claimed that the neural network can achieve consistent quality in varying welding conditions on the basis of different input data (root face, root gap, and weld bead temperature). In practice, the developed system can potentially reduce welding manufacturing costs by reducing labor input and increasing arc time. Additionally, the cost efficiency is improved by a reduction in rework and scrap because of more consistent product quality. However, the system is not without some drawbacks. The training process of the ANN system takes significant time, and the system needs to be trained for each application. Moreover, groove preparation needs to be sufficiently high quality to enable the system to function reliably.

Further research can be done to investigate the suitability of the ANN-controlled system for other welding positions, seam types, and materials. Overall, the system could provide significant cost savings and improved quality in GMAW butt weld applications. The optimal application field of the system would be continuous long welds with high-quality requirements. The ANN system in this work used supervised offline learning; thus, the investigation of automated online learning sequences (also known as self-learning systems) for welding would be a natural topic of further study.

\section{Conclusion}

This study was set out to determine whether the ANN-based welding parameter control system can optimize the welding parameters to get consistent welding output in varying welding conditions. The results of the study indicate that a laser sensor is a suitable tool for the detection and measurement of the root gap and root face of the weld seam for welding process control purposes. The findings of this study provide additional evidence that the artificial intelligence system can react to the varying welding conditions effectively. The results of the study confirm that the ANN-based decision-making system could provide consistent weld output in varying welding conditions. The study supports the hypothesis that the neural network is suitable to control algorithm for GMAW application in practice. However, the current study has only examined one type of sensor, welding process, and joint type. More practical orientated research needs to be conducted to verify the complete suitability for practical welding applications.

Acknowledgements Open access funding provided by LUT University.

Open Access This article is distributed under the terms of the Creative Commons Attribution 4.0 International License (http:// creativecommons.org/licenses/by/4.0/), which permits unrestricted use, distribution, and reproduction in any medium, provided you give appropriate credit to the original author(s) and the source, provide a link to the Creative Commons license, and indicate if changes were made.

\section{References}

1. Gyasi EA, Kah P, Wu H, Kesse MA (2017) Modeling of an artificial intelligence system to predict structural integrity in robotic GMAW of UHSS fillet welded joints. Int J Adv Manuf Technol 93:1139 1155. https://doi.org/10.1007/s00170-017-0554-0 
2. Kah P, Shrestha M, Hiltunen E, Martikainen J (2015) Robotic arc welding sensors and programming in industrial applications. Int $\mathrm{J}$ Mech Mater Eng 10:13. https://doi.org/10.1186/s40712-015-0042-y

3. Åstrand E, Öberg AE, Jonsson B (2013) Cost affecting factors related to fillet joints. In: Jármai K, Farkas J (eds) Des. Fabr. Econ. Met. Struct. Springer Berlin Heidelberg, Berlin, Heidelberg, pp 431-435

4. Öberg AE, Sikström F (2017) Barriers for industrial implementation of in-process monitoring of weld penetration for quality control. Int J Adv Manuf Technol 91:2427-2434. https://doi.org/10. 1007/s00170-016-9894-4

5. Björk T, Samuelsson J, Marquis G (2008) The need for a weld quality system for fatigue loaded structures. Weld World. https:// doi.org/10.1007/BF03266615

6. Jonsson B, Samuelsson J, Marquis GB (2011) Development of weld quality criteria based on fatigue performance development of weld quality criteria based on fatigue performance. Weld World. https://doi.org/10.1007/BF03321545

7. Stenberg T, Barsoum Z, Åstrand E, Öberg AE, Schneider C, Hedegård J (2017) Quality control and assurance in fabrication of welded structures subjected to fatigue loading. Weld World. https:// doi.org/10.1007/s40194-017-0490-5

8. Karkhin V (2013) Thermal processes in welding. St. Petersburg Polytechnical University, St. Petersburg

9. Michailov V, Karkhin VA, Petrov PI (2016) Principles of welding. Polytechnic Univ. Publ, St. Petersburg https://opus4.kobv.de/ opus4-UBICO/frontdoor/index/index/docId/18903

10. Chen SB, Lv N (2014) Research evolution on intelligentized technologies for arc welding process. J Manuf Process 16:109-122. https://doi.org/10.1016/j.jmapro.2013.07.002

11. Liu F-Q, Wang Z-Y, Wang X-J, Ji Y (2015) Tacked weld point recognition from geometrical features. In: Tarn T-J, Chen S-B, Chen X-Q (eds) Robot. Welding, Intell. Autom. RWIA'2014. Springer International Publishing, Cham, pp 47-56. https://doi. org/10.1007/978-3-319-18997-0_3

12. Kim JW, Lee JY (2008) A control system for uniform bead in fillet arc welding on tack welds. J Mech Sci Technol 22:1520-1526. https://doi.org/10.1007/s12206-008-0433-6

13. Penttilä S, Kah P, Ratava J, Pirinen M (2017) Penetration and quality control with artificial neural network welding system. In: International Society of Offshore and Polar Engineers, pp 54-61

14. Öberg AE, Åstrand E (2018) Variation in welding procedure specification approach and its effect on productivity. Procedia Manuf 25:412-417. https://doi.org/10.1016/j.promfg.2018.06.111

15. Åstrand E, Stenberg T, Jonsson B, Barsoum Z (2016) Welding procedures for fatigue life improvement of the weld toe. Weld World. https://doi.org/10.1007/s40194-016-0309-9

16. Ebert-Spiegel M, Goecke SF, Rethmeier M (2014) Efficient gap filling in MAG welding using optical sensors. Weld World 58: 637-647. https://doi.org/10.1007/s40194-014-0145-8

17. Chen Z, Song Y, Zhang J, Zhang W, Jiang L, Xia X (2007) Laser vision sensing based on adaptive welding for aluminum alloy. Front Mech Eng China 2:218-223. https://doi.org/10.1007/s11465-007-0038-2

18. Garašić I (2015) Sensors and their classification in the fusion welding technology. Teh Vjesn Gaz 22:1069-1074. https://doi. org/10.17559/TV-20131127091427

19. Rios-Cabrera R, Morales-Diaz AB, Aviles-Viñas JF, Lopez-Juarez I (2016) Robotic GMAW online learning: issues and experiments. Int J Adv Manuf Technol 87:2113-2134. https://doi.org/10.1007/ s00170-016-8618-0

20. Horvat J, Prezelj J, Polajnar I, Cudina M (2011) Monitoring gas metal arc welding process by using audible sound signal, Stroj. Vestnik/ Journal Mech Eng 57. https://doi.org/10.5545/sv-jme.2010.181

21. Huang W, Kovacevic R (2011) A laser-based vision system for weld quality inspection. Sensors. 11:506-521. https://doi.org/10. 3390/s110100506
22. Jain LC, Seera M, Lim CP, Balasubramaniam P (2014) A review of online learning in supervised neural networks. Neural Comput Applic 25:491-509. https://doi.org/10.1007/s00521-013-1534-4

23. Pires JN, Loureiro A, Bölmsjo G (2006) Welding robots: technology, system issues and applications. https://doi.org/10.1007/184628-191-1

24. Muhammad J, Altun H, Abo-Serie E (2017) Welding seam profiling techniques based on active vision sensing for intelligent robotic welding. Int J Adv Manuf Technol 88:127-145. https://doi.org/10. 1007/s00170-016-8707-0

25. Gu WP, Xiong ZY, Wan W (2013) Autonomous seam acquisition and tracking system for multi-pass welding based on vision sensor. Int J Adv Manuf Technol 69:451-460. https://doi.org/10.1007/ s00170-013-5034-6

26. Shahabi H, Kolahan F (2016) A novel approach for monitoring and improving the quality of welded joint in gas metal arc welding process using adaptive neuro-fuzzy systems. Proc Inst Mech Eng Part B J Eng Manuf 230:1489-1501. https://doi.org/10.1177/ 0954405415607381

27. Azadi Moghaddam M, Golmezergi R, Kolahan F (2016) Multivariable measurements and optimization of GMAW parameters for API-X42 steel alloy using a hybrid BPNN-PSO approach. Meas J Int Meas Confed 92:279-287. https://doi.org/10.1016/j. measurement.2016.05.049

28. Chandrasekhar N, Vasudevan M, Bhaduri AK, Jayakumar T (2013) Intelligent modeling for estimating weld bead width and depth of penetration from infra-red thermal images of the weld pool. J Intell Manuf 26:59-71. https://doi.org/10.1007/s10845-013-0762-x

29. Chokkalingham S, Chandrasekhar N, Vasudevan M (2012) Predicting the depth of penetration and weld bead width from the infra red thermal image of the weld pool using artificial neural network modeling. J Intell Manuf 23:1995-2001. https://doi.org/ 10.1007/s10845-011-0526-4

30. Nagesh DS, Datta GL (2010) Genetic algorithm for optimization of welding variables for height to width ratio and application of ANN for prediction of bead geometry for TIG welding process. Appl Soft Comput J 10:897-907. https://doi.org/10.1016/j.asoc.2009.10.007

31. Nagesh DS, Datta GL (2002) Prediction of weld bead geometry and penetration in shielded metal-arc welding using artificial neural networks. J Mater Process Technol 123:303-312. https://doi.org/ 10.1016/S0924-0136(02)00101-2

32. Dhas ER, Kumanan S, Jesuthanam CP (2012) Prediction of weld quality using intelligent decision making tools. Artif Intell Res 1: 131-148. https://doi.org/10.5430/air.v1n2p131

33. Chen H, Lv F, Lin T, Chen S (2009) Closed-loop control of robotic arc welding system with full-penetration monitoring. J Intell Robot Syst Theory Appl 56:565-578. https://doi.org/10.1007/s10846-009-9329-7

34. Ratava J, Penttilä S, Lohtander M, Kah P (2018) Optical measurement of groove geometry. Procedia Manuf 25:111-117. https://doi. org/10.1016/j.promfg.2018.06.064

35. ISO (2014) ISO 5817 Welding, fusion-welded joints steel, nickel, titan. their alloy. (Beam Weld. Exclud. Levels Imperfections. 2014

36. Lawrence S, Giles CL (2000) Overfitting and neural networks: conjugate gradient and backpropagation. In: Proc. IEEE-INNSENNS Int. Jt. Conf. Neural Networks. IJCNN 2000, vol 1. Neural Comput. New Challenges Perspect, New Millenn, pp 114-119. https://doi.org/10.1109/IJCNN.2000.857823

37. Rynkiewicz J (2012) General bound of overfitting for MLP regression models. Neurocomputing. 90:106-110. https://doi.org/10. 1016/j.neucom.2011.11.028

38. A. E112-13 (2013) Standard test methods for determining average grain size, ASTM Int

Publisher's note Springer Nature remains neutral with regard to jurisdictional claims in published maps and institutional affiliations. 